\title{
Investigation of Impact of Contingencies on Power Plant and Transmission Lines
}

\author{
UGWU K .I \\ Department of Electrical Electronic Engineering, \\ Enugu State University of Science \& technology (ESUT), Enugu, Nigeria
}

\begin{abstract}
Contingency analysis are widely applied to predict the effect of outages in power systems, like tripping of equipment in power plants and transmission lines. Using off line analysis to predict the effect of individual contingency is a tedious task on power system containing large number of components. Practically, only selected contingencies will lead to severe conditions in power system, like violation of voltage and active power flow limits. Simultaneously, the value of active power flow before and after severe transmission and power plant contingencies was analysed using Genetic Eigenvalue Analysis Technique. This was achieved by simulating the Simulink of Nigerian 330KV 48 bus power system using m-file programme in MATLAB environment.The result of the simulation for the power flow solution for transmission line outage contingencies shows that the voltage trajectory at bus 11 stood at 0.3934 p.u, at bus 15 is 0.4986 p.u, and bus of 23 is 0.4647 p.u while for the contingencies on power plant, there voltage trajectories stood at $0.2342 \mathrm{p}$.u for bus $11,0.3987 \mathrm{p} . \mathrm{u}$ for bus 23 . The result shows that the impact on power plant is higher than that of transmission line by $40 \%, 20 \%, 14 \%$ for sampled buses 11,15 , and 23 respectively.
\end{abstract}

Keywords: Power Stability- Genetic Eigenvalue, Load flow

DOI: $10.7176 / \mathrm{JETP} / 11-1-04$

Publication date: January $31^{\text {st }} 2021$

\subsection{INTRODUCTION:}

This paper presents an efficient and realistic contingency analysis method of Nigerian 330KV power system using Genetic Eigenvalue Technique.

The purpose and usefulness of small signal stability investigation is to understand the characteristics of system behavior with minimal error while significantly decreasing both the complexity and scale of computation involved. With the size and complexity of power systems ever increasing, the computational effort involved can easily surpass feasible limits even when utilizing computers and other speed processing equipment. As a result, simplified techniques can be used to yield rather precise and useful characteristics of a system that in turn, indicate system response and behavior, all while greatly reducing the effort involved. The term "small signal" reflects the minor disturbances used to evaluate the simplified system model. Small disturbances within a system are common and refer to disturbances that allow representation of the nonlinear system as a linearized model Hoang[7]. These disturbances can include load changes, and various oscillations and resonance within a power system. So what is the general idea behind small signal stability? As mentioned earlier, small signal stability takes a power system relation involving complex nonlinearities and analyzes a stable system around an equilibrium point as it experiences small perturbations. This is done by linearizing the system around a point or utilizing other techniques that eliminate complex dynamics. This effectively takes a nonlinear system and transforms it into a linear system where many assumptions and simplifications can be made. It is important to note that the linear approximation is only made at a certain point and changes at each different point in time. Conversely, transient stability analysis refers to the analysis of power systems accounting for the nonlinear dynamics of the modeled system. Larger disturbances justify analysis of the system's response at different operating points as the system characteristics change. Transient stability analysis differs in the type and degree of disturbance but can often decompose into a state similar to small signal instability. Concerning transient instability, synchronization issues can result from first swing issues or long term end state instability can result from growing oscillations.

\subsection{REVIEW OF OTHER RESEARCH WORK}

Taguchi method has been employed to solve economic dispatch problems [5].Power system stabilizer (PSS) PSS provide better damping over a wide range of operating conditions. Finally, it can be concluded that the Taguchi principle can be effectively employed to achieve an intrinsic robustness in the PSS parameters against variations in operating conditions.

The model done by[6], was tested on the 16-machine in 68- bus New England-New York interconnected system, and its effectiveness was established during the Eigenvalue analysis and nonlinear simulation results. In addition, the results demonstrated that the minimum damping ratio can be increased, and the number of PSSs can be reduced by adding UPFC-based stabilizer to the system.

The work of[7],on optimization problem was also formulated to determine PSS placement. The objective was 
to minimize the PSS control gains with constraints to move the unstable eig10nvalues to the stable region while not changing the stable eigenvalues. This approach assumed that PSSs were installed at every machine.

During severe disturbance, a PSS may actually cause the generator under its control to lose synchronism in an attempt to control its excitation [8].

GAGenetic Algorithm has been applied successfully to various power system problems and the recent approach is to integrate the use of GA and fuzzy logic systems in order to design power system stabilizer [3].The coordination between genetic based fuzzy logic power system stabilizer (GFLPSS) and CPSS provide good damping characteristics during small disturbance and large disturbances for local as well as inter area modes of oscillations

The closed-loop performance of the system model was evaluated for an input disturbance in the mechanical torque. The results show that the optimal output controller exhibits better performance than the conventional controller. Results also show the robustness and the validity of the output optimal controller. The usage of optimal control is discussed[9].

\subsection{RESEARCH METHODOLOGY:}

\section{- 3OKV GRID NETWORK}

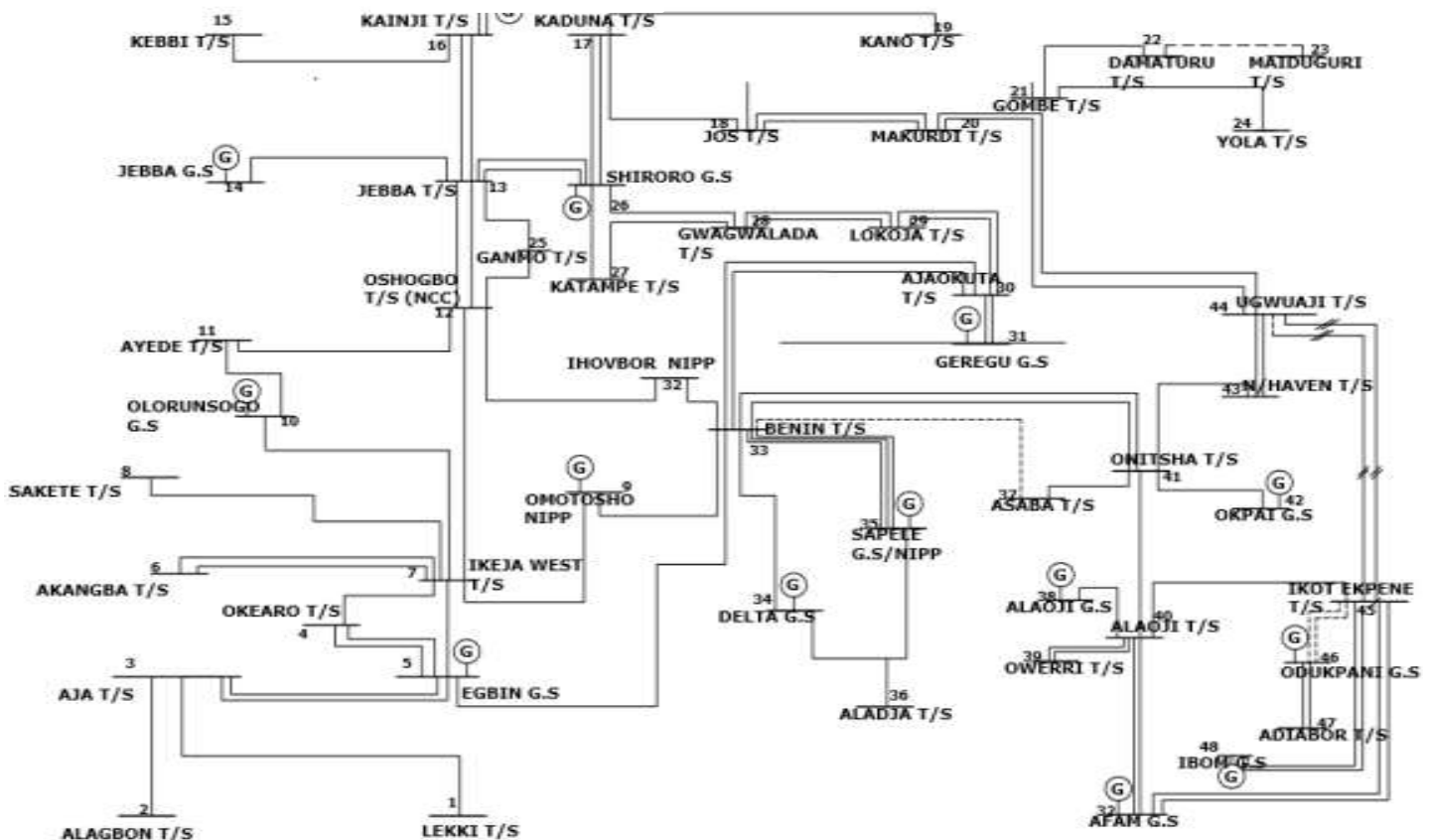

Figure 1: The Nigerian 330kv, 48-Bus Line Diagram

The Nigerian $330 \mathrm{KV}, 48$-bus system was modeled as the case study power system for the simulation test, to validate the stability analysis technique and the proposed power system damping controller. The MATLAB Simulink environment is used for the modeling and development of the case study interconnected power system damping controller and for programming the genetic-eigenvalue stability analyzer. For the testing and evaluation of the solution, different transient disturbances were simulated and injected into the MATLAB model of the case study power grid to investigate the performance of the system. Simulations are carried out to determine the effect on the power system angle stability, voltage stability and frequency stability of the case study of power system. 


\subsection{Development of Simulink Model of the Case Study Power system}
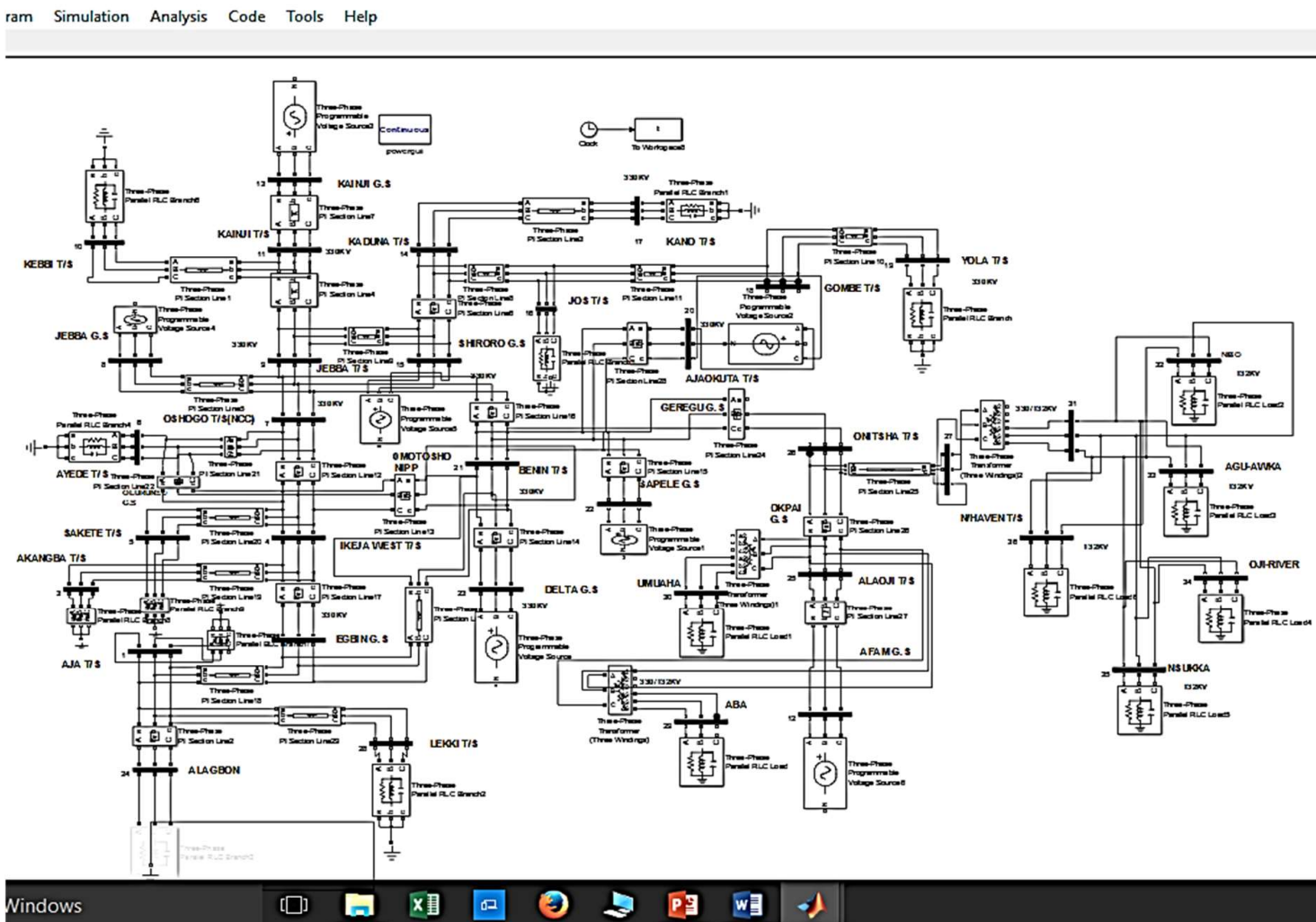

Figure 2:Simulink Model of the Nigerian 330KV Power System

The Simulink model of Nigerian 330KV, 48-bus interconnected system was developed for load flow studies, to see the base case voltage profile of the network and for further simulations on the implementation of genetic eigenvalue algorithm

The Nigerian 330KV, 48-bus was modeled using MATLAB Simulink tool box. This shows 48-bus for further simulations on the network as shown on fig 2.System data for the existing 48-bus Nigeria 330kV power networks obtained from Power Transmission Company of Nigeria (TCN) Osogbo, were used as input data which provided the values of series impedances, admittances of the transmission lines, transformer ratings and impedances required for the power/load flow study. These parameters were modeled and simulated in MATLAB/SIMULINK power system analysis using Newton-Raphson power flow algorithm.

\subsection{Load/ Power Flow solution for 48-bus network.}

Nigerian 330KV 48-bus modeled using MATLAB/SIMULINK Simulation power toolbox.The MATLAB M-file program Pflow was then used to carry out load flow solution of the 48-bus 330KV interconnected power system. The source code of the Pflowsoftware. The Pflow load flow software implements the Newton-Raphson load flow algorithm. The load flow was done to obtain the base case voltage profile of the case study power system. From the load flow investigation, it can be seen that 27 buses are below the $5 \%$ voltage drop limit. This shows substantial weakness in the power system under investigation. However, this does not give much information regarding the distribution of instabilities in the system. The power system stability is now analyzed under generator outage condition. The MATLAB SIMULINK synchronous generator block was configured to trip the generator within a set time. The block is configured to trip generator 4 within $1.5 \mathrm{secs}$ of the simulation. The result of associated eigenvalue analysis is as analyzed below.

\subsection{Mathematical Model of Power Flow and Eigenvalue Analysis}

Power system matrices are required for the stability analyses of genetic eigenvalue analysis program, hence the mathematical model were derived as shown

$$
I=Y V=\frac{S *}{V *}
$$




\section{Where \\ I $=$ Modal current injection matrix \\ $\mathrm{Y}=$ System modal admittance \\ $\mathrm{V} \quad=\quad$ Unknown complex mode voltage vector \\ $\mathrm{S} \quad=\quad$ Apparent power modal injection vector representing specified load and generation of nodes. \\ Where

$$
\mathrm{S}=\mathrm{P}+\mathrm{JQ}
$$

The using Newton-Raphson method from (3), the equation for node K (bus K) is written as:

$$
\begin{aligned}
& I_{K} \sum_{m=1}^{n} Y_{K M} V_{m} \\
& P_{K}+J Q_{k}=V_{K} I_{K}=V_{K} \sum_{m=1}^{n} Y_{K M} V_{m}
\end{aligned}
$$

Where

$$
\begin{aligned}
& \mathrm{M}=1,2 \ldots \ldots \ldots \mathrm{n} \\
& \mathrm{n}=\text { number of buses } \\
& V_{k} \text { is the voltage of the } \mathrm{K} \text { bus }
\end{aligned}
$$

$Y_{K M}$ is the element of the admittance bus equating the real and imaginary parts

$$
\begin{aligned}
& P_{K}=K_{e}\left(V_{K}\left(\sum_{m=1}^{n} Y^{*}{ }_{K M} V^{*}{ }_{K}\right)\right) \\
& Q_{K}=I_{M}\left(V_{K}\left(\sum_{m=1}^{n} Y^{*}{ }_{K M} V^{*}{ }_{K}\right)\right)
\end{aligned}
$$

Where

$P_{K}$ is the real power

$Q_{K}$ is the reactive power with the following notation:

$V_{K}=\left|V_{K}\right| e^{j q_{k}}, V_{M}=\left|V_{m}\right| e^{j q_{m}}, Y_{K M^{2}}\left|Y_{K M}\right| e^{j t}$

Where

$\left|V_{K}\right|_{\text {is the magnitude of the voltage }}$

$\delta_{k}$ is the angle of the voltage

$\delta_{k m}$ is the load angle

Substituting for $V_{k}, V_{m}$, and $Y_{k m}$ in equation

$P_{K}+J Q_{K}=\left|V_{K}\right| e^{j d_{k}} \sum_{m=1}^{n}\left|V_{k}\right|\left|Y_{K M}\right| e^{j q_{k m}}$

$P_{K}+J Q_{K}=\left|V_{K}\right| \sum_{m=1}^{n}\left|V_{k}\right|\left|Y_{K M}\right| e^{j\left(\delta_{k}-\delta_{m}=\delta_{k m}\right)}$

Or

$P_{K}+J Q_{K}=\left|V_{K}\right| \sum_{m=1}^{n}\left|V_{k}\right|\left|Y_{K M}\right|<\left(\delta_{k}-\delta_{k}-\delta_{k m}\right)$

Or

$+J Q_{K}=\left|V_{K}\right| \sum_{m=1}^{n}\left|V_{k}\right|\left|Y_{K M}\right|\left(\cos \hat{\varphi}_{k}-\delta_{m}-Q_{k m}\right)+J \sin \left(\delta_{k}-\delta_{m}-Q_{k m}\right)$

Separating the real and imaginary parts of above equations to get real and reactive power 


$$
\begin{gathered}
P_{K}=\left|V_{K}\right| \sum_{m=1}^{n}\left|V_{k}\right|\left|Y_{K M}\right| \cos \left(\delta_{k}-\delta_{m}-Q_{k m}\right) \\
Q_{K}=\left|V_{K}\right| \sum_{m=1}^{n}\left|V_{k}\right|\left|Y_{K M}\right| \sin \left(\delta_{k}-\delta_{m}-Q_{k m}\right)
\end{gathered}
$$

The mismatch power at bus $\mathrm{K}$ is given by:

$\Delta P_{K}=P_{K}^{\text {sch }}-P_{K}$

$\Delta \mathrm{Q}_{K}=Q_{K}^{\text {sch }}-Q_{K}$

The $P_{K}$ and $Q_{K}$ are calculated from equations (3.13) and (3.14)

The Newton - Raphson method solves the partitioned matrix equation:

$$
\left[\frac{\Delta P}{\Delta Q}\right]=J\left[\frac{\Delta Q}{\Delta V}\right]
$$

Where

$\Delta P$ and $\Delta Q=$ mismatch active and reactive power vectors

$\Delta V$ and $\Delta Q=$ unknown voltage magnitude and angle correction vectors

$\mathrm{J}=$ Jacobean matrix of partial derivative terms

The eigenvalues associated with a mode of voltage and reactive power variation can provide a relative measure of proximity to voltage instability. Then, the participation factor can be used to find out the weak nodes or buses in the system.

Equation (15) can be written as:

$$
\left[\frac{\Delta P}{\Delta Q}\right]=\left[\begin{array}{ll}
\frac{J_{11}}{J_{21}} & \frac{J_{12}}{J_{22}}
\end{array}\right]\left[\frac{\Delta Q}{\Delta V}\right]
$$

By letting $\Delta P=O_{\text {in Equation (3.18) }}$

$$
\Delta P=O=J_{11} \Delta \theta+J_{12} \Delta V
$$

Where

$$
\begin{aligned}
& \Delta \theta=-J_{11}^{-1} J_{12} \Delta V \\
& \Delta \theta=-J_{21} \Delta \theta+J_{22} \Delta V
\end{aligned}
$$

Subtracting equation (17) in equation (21)

$$
\Delta \theta=-J_{R} \Delta V
$$

Where

$$
J_{R}=\left[J_{22}-J_{21} J_{11}^{-1} J_{12}\right] \quad J_{R} \text { is the reduced jacobian matrix of the system }
$$

Equation (13) can be written as

$$
\Delta V=J_{R}^{-1} \Delta Q
$$

The matrix $J_{R}$ represents the linearized relationship between the incremental changes in bus voltage $(\Delta V)$ and bus reactive power injection $(\Delta Q)$. It is well known that the system voltage is affected by both real and reactive power variations. In order to focus the study of the reactive demand and supply problem of the system as well as minimize computations effort by reducing dimension of the computation effort by reducing dimensions of the Jacobean Matrix $\mathrm{J}$ the real power $(\Delta P=O)$ and angle part from the system his equation (3.13) are eliminated.. 
The eigenvalues and Eigen-vectors of the reduced order Jacobean matrix $\left(J_{R}\right)$ are used for the power system stability characterized analysis. Instability can be detected by identifying modes of the eigenvalues matrix $\left(J_{R}\right)$. The magnitude of the eigenvalues provides a relative measure of proximity to instability. The eigenvectors on the other hand present information related to the mechanism of loss of voltage stability.

Modal analysis of $\left(J_{R}\right)$ results in the following

$\left(J_{R}\right)=\tau \phi \xi_{\text {eigl }}$

\section{Notation used in the flow chart:}

$A=\left(J_{R}\right)$ is the system matrix, based on the model of the power system

$H$ is matrix having orthonormal columns

$V$ is matrix having orthonormal columns (can also be an invariant sup space of matrix A)

$x, f$ are the Ritz vectors

$\lambda$ is the eigenvalues

$\sigma$ is a shift

I is the identity matrix

$\xi_{\text {eigl }}=$ left eigenvector matrix of $\left(J_{R}\right)$

$\mathrm{X}=$ diagonal eigenvalue matrix of $\left(J_{R}\right)$

Equation (22) can be written as:

$J_{R}^{-1}=\phi \xi_{\text {eigl }}$

The appropriate definition and determination as to which modes or buses participates in the selected mode become very important. The participation factor is computed to identify the weakest nodes or lead buses that are making significant contribution to the selected modes.

The participation factor is given by

$$
X_{i}=\frac{\sum \phi_{i} \xi_{e i \lambda l}}{\lambda_{i}} \Delta Q
$$

Where $\lambda_{i}$ is the $i^{\text {th }}$ eigenvalue, $\phi_{i}$ is the column right eigenvector and is the $i^{\text {th }}$ column right eigenvector and $\xi_{e i \lambda l}$ is the $i^{\text {th }}$ row left eigenvector of matrix $\left(J_{R}\right)$

Each eigenvalue and corresponding right and left eigenvectors $\phi_{i}$ and $\xi_{\text {eill }}$, defines the $i^{\text {th }}$ modes of the system. 


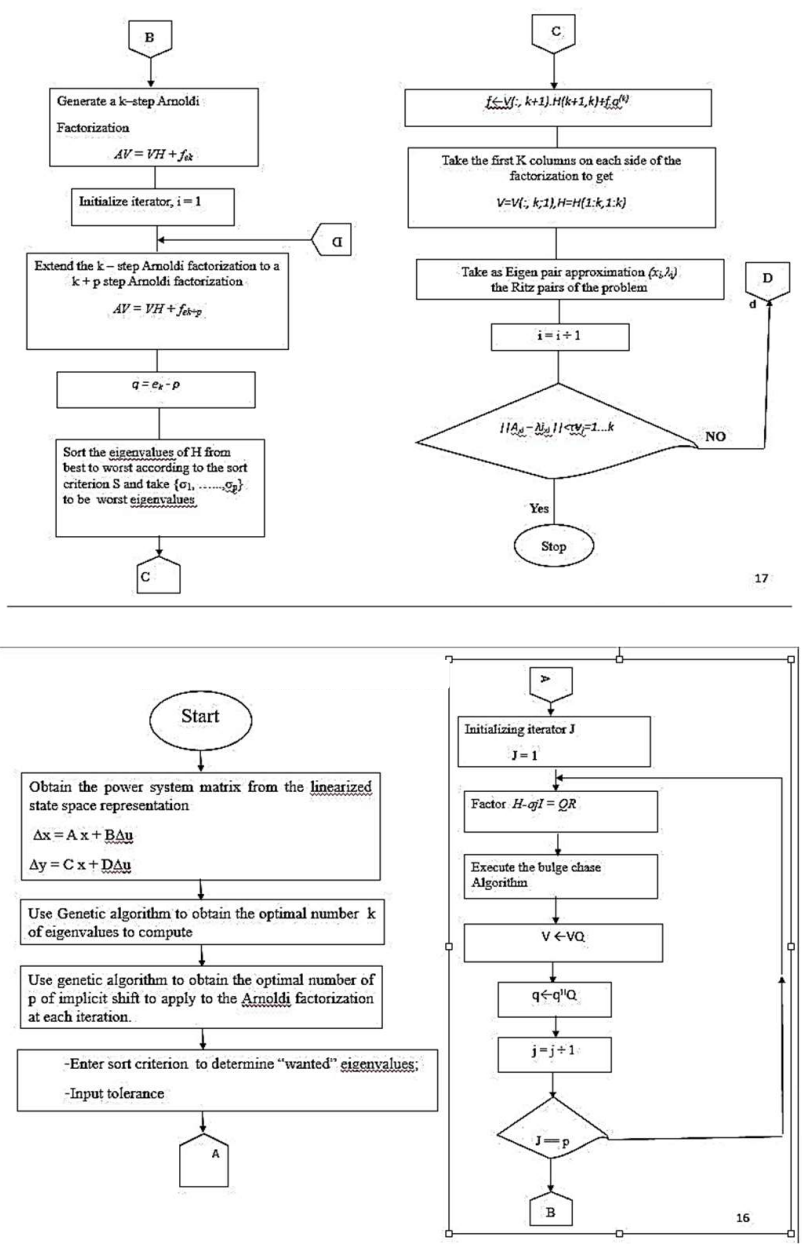

Fig 3: Flow Chart for Genetic Eigenvalue programming

The flow chart for the implementation of the Genetic eigenvalue algorithm programming was developed as shown in fig 3 contains an arranged parameters for simulation and generation of eigenvalues, and computation of participation factors and damping ratios of the Nigerian 330KV 48-Bus network from the network Simulink of figure 3. The genetic eigenvalue stability analysis program, the eigenvalues of the network are extracted, participation factors and damping ratios of the generators were equally computed by the program.

\section{RESULTS}

The base data for this paper are system parameters of Nigerian 330KV 48-bus system from Transmission Company of Nigeria. There are 14 synchronous generators in the system. The base voltage is $330 \mathrm{KVA}$ and 100MVA. The generator, line and bus parameters used for simulation and computations are listed in table 1.

\section{Table 1: The Generator Parameters}

\begin{tabular}{|l|l|l|l|l|}
\hline S/No & Generator Station & Generation & Rated Voltage & Voltage P.U \\
\hline 1 & Kainji & $292 \mathrm{Mw}$ & $332 \mathrm{KV}$ & 1.0060 \\
\hline 2 & Jebba & $404 \mathrm{Mw}$ & $312 \mathrm{KV}$ & 0.9455 \\
\hline 3 & Shiroro & $450 \mathrm{Mw}$ & $320 \mathrm{KV}$ & 0.9697 \\
\hline 4 & Egbini & $611 \mathrm{Mw}$ & $335 \mathrm{KV}$ & 1.0151 \\
\hline 5 & Sapele & $68 \mathrm{Mw}$ & $332 \mathrm{KV}$ & 1.0060 \\
\hline 6 & Delta & $470 \mathrm{Mw}$ & $318 \mathrm{KV}$ & 0.9636 \\
\hline 7 & Geregu & $144 \mathrm{Mw}$ & $319 \mathrm{KV}$ & 0.9677 \\
\hline 8 & Omotosho & $187.5 \mathrm{Mw}$ & $305 \mathrm{KV}$ & 0.9242 \\
\hline 9 & Olominsogo gas & $163.6 \mathrm{Mw}$ & $300 \mathrm{KV}$ & 0.9090 \\
\hline 10 & Geregu NIPP & $150 \mathrm{Mw}$ & $331 \mathrm{KV}$ & 1.0030 \\
\hline 11 & Sapele NIPP & $113.1 \mathrm{Mw}$ & $320 \mathrm{KV}$ & 0.9692 \\
\hline 12 & Olorunsogo NIPP & $130.9 \mathrm{Mw}$ & $316 \mathrm{KV}$ & 09576 \\
\hline
\end{tabular}




\begin{tabular}{|l|l|l|l|l|}
\hline S/No & Generator Station & Generation & Rated Voltage & Voltage P.U \\
\hline 13 & Omotosho NIPP & $228 \mathrm{Mw}$ & $347 \mathrm{KV}$ & 1.05151 \\
\hline 14 & Okapia & $363 \mathrm{Mw}$ & $331 \mathrm{KV}$ & 1.0030 \\
\hline
\end{tabular}

\section{Bus Parameter}

\section{System Details}

MVA Base $=100 \mathrm{MVA}$

System frequency $=50 \mathrm{~Hz}$

$2=$ Generator Bus (pv)

Bus Nominal Voltage $=330 \mathrm{KV}$

3 = System Wiring Bus

Bus Maximum Voltage $=330.5 \mathrm{kv}$

Table 2: Bus Parameters

\begin{tabular}{|c|c|c|c|c|c|c|c|}
\hline Bus No & 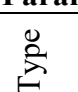 & $\mathrm{Max}-\mathrm{Vm}-\mathrm{Pu}$ & Min-Vm-Pu & Area & $\begin{array}{l}\text { D̃ } \\
\text { N }\end{array}$ & In-Service & Vn-KV \\
\hline 1 & 2 & 1.05 & 0.95 & 1 & 1 & True & $330 \mathrm{KV}$ \\
\hline 2 & 2 & 1.05 & 0.95 & 1 & 1 & True & $330 \mathrm{KV}$ \\
\hline 3 & 2 & 1.05 & 0.95 & 1 & 1 & True & $330 \mathrm{KV}$ \\
\hline 4 & 2 & 1.05 & 0.95 & 1 & 1 & True & $330 \mathrm{KV}$ \\
\hline 5 & 2 & 1.05 & 0.95 & 1 & 1 & True & $330 \mathrm{KV}$ \\
\hline 6 & 2 & 1.05 & 0.95 & 1 & 1 & True & $330 \mathrm{KV}$ \\
\hline 7 & 2 & 1.05 & 0.95 & 1 & 1 & True & $330 \mathrm{KV}$ \\
\hline 8 & 2 & 1.05 & 0.95 & 1 & 1 & True & $330 \mathrm{KV}$ \\
\hline 9 & 2 & 1.05 & 0.95 & 1 & 1 & True & $330 \mathrm{KV}$ \\
\hline 10 & 2 & 1.05 & 0.95 & 1 & 1 & True & $330 \mathrm{KV}$ \\
\hline 11 & 2 & 1.05 & 0.95 & 1 & 1 & True & $330 \mathrm{KV}$ \\
\hline 12 & 2 & 1.05 & 0.95 & 1 & 1 & True & $330 \mathrm{KV}$ \\
\hline 13 & 2 & 1.05 & 0.95 & 1 & 1 & True & $330 \mathrm{KV}$ \\
\hline 14 & 2 & 1.05 & 0.95 & 1 & 1 & True & $330 \mathrm{KV}$ \\
\hline 15 & 2 & 1.05 & 0.95 & 1 & 1 & True & $330 \mathrm{KV}$ \\
\hline 16 & 2 & 1.05 & 0.95 & 1 & 1 & True & $330 \mathrm{KV}$ \\
\hline 17 & 2 & 1.05 & 0.95 & 1 & 1 & True & $330 \mathrm{KV}$ \\
\hline 18 & 2 & 1.05 & 0.95 & 1 & 1 & True & $330 \mathrm{KV}$ \\
\hline 19 & 2 & 1.05 & 0.95 & 1 & 1 & True & $330 \mathrm{KV}$ \\
\hline 20 & 2 & 1.05 & 0.95 & 1 & 1 & True & $330 \mathrm{KV}$ \\
\hline 21 & 2 & 1.05 & 0.95 & 1 & 1 & True & $330 \mathrm{KV}$ \\
\hline 22 & 2 & 1.05 & 0.95 & 1 & 1 & True & $330 \mathrm{KV}$ \\
\hline 23 & 2 & 1.05 & 0.95 & 1 & 1 & True & $330 \mathrm{KV}$ \\
\hline 24 & 2 & 1.05 & 0.95 & 1 & 1 & True & $330 \mathrm{KV}$ \\
\hline 25 & 2 & 1.05 & 0.95 & 1 & 1 & True & $330 \mathrm{KV}$ \\
\hline 26 & 2 & 1.05 & 0.95 & 1 & 1 & True & $330 \mathrm{KV}$ \\
\hline 27 & 2 & 1.05 & 0.95 & 1 & 1 & True & $330 \mathrm{KV}$ \\
\hline 28 & 2 & 1.05 & 0.95 & 1 & 1 & True & $330 \mathrm{KV}$ \\
\hline 29 & 2 & 1.05 & 0.95 & 1 & 1 & True & $330 \mathrm{KV}$ \\
\hline 30 & 2 & 1.05 & 0.95 & 1 & 1 & True & $330 \mathrm{KV}$ \\
\hline 31 & 2 & 1.05 & 0.95 & 1 & 1 & True & $330 \mathrm{KV}$ \\
\hline 32 & 2 & 1.05 & 0.95 & 1 & 1 & True & $330 \mathrm{KV}$ \\
\hline 33 & 2 & 1.05 & 0.95 & 1 & 1 & True & $330 \mathrm{KV}$ \\
\hline 34 & 2 & 1.05 & 0.95 & 1 & 1 & True & $330 \mathrm{KV}$ \\
\hline 35 & 2 & 1.05 & 0.95 & 1 & 1 & True & $330 \mathrm{KV}$ \\
\hline 36 & 2 & 1.05 & 0.95 & 1 & 1 & True & $330 \mathrm{KV}$ \\
\hline 37 & 2 & 1.05 & 0.95 & 1 & 1 & True & $330 \mathrm{KV}$ \\
\hline 38 & 2 & 1.05 & 0.95 & 1 & 1 & True & $330 \mathrm{KV}$ \\
\hline 39 & 2 & 1.05 & 0.95 & 1 & 1 & True & $330 \mathrm{KV}$ \\
\hline 40 & 2 & 1.05 & 0.95 & 1 & 1 & True & $330 \mathrm{KV}$ \\
\hline 41 & 2 & 1.05 & 0.95 & 1 & 1 & True & $330 \mathrm{KV}$ \\
\hline 42 & 2 & 1.05 & 0.95 & 1 & 1 & True & $330 \mathrm{KV}$ \\
\hline
\end{tabular}

Type:

$1=$ Load Bus 


\begin{tabular}{|c|c|c|c|c|c|c|c|}
\hline Bus No & $\underset{\leftarrow}{\stackrel{\Xi}{\leftrightarrows}}$ & $\mathrm{Max}-\mathrm{Vm}-\mathrm{Pu}$ & Min- $\mathrm{Vm}-\mathrm{Pu}$ & Area & 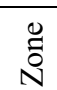 & In-Service & Vn-KV \\
\hline 43 & 2 & 1.05 & 0.95 & 1 & 1 & True & $330 \mathrm{KV}$ \\
\hline 44 & 2 & 1.05 & 0.95 & 1 & 1 & True & $330 \mathrm{KV}$ \\
\hline 45 & 2 & 1.05 & 0.95 & 1 & 1 & True & $330 \mathrm{KV}$ \\
\hline 46 & 2 & 1.05 & 0.95 & 1 & 1 & True & $330 \mathrm{KV}$ \\
\hline 47 & 2 & 1.05 & 0.95 & 1 & 1 & True & $330 \mathrm{KV}$ \\
\hline 48 & 2 & 1.05 & 0.95 & 1 & 1 & True & $330 \mathrm{KV}$ \\
\hline
\end{tabular}

Table 3: Load Flow Result for the Plot of the Profile of the Base Case Power System

\begin{tabular}{|c|c|c|c|c|c|}
\hline BUS & Voltage $(p, u)$ & Angle(rad) & $\begin{array}{c}P \\
\operatorname{gen}(p, u)\end{array}$ & $\begin{array}{c}\mathbf{Q} \\
\operatorname{gen}(p \cdot u)\end{array}$ & $\begin{array}{c}P \\
\operatorname{load}(p, u)\end{array}$ \\
\hline 1 & 0.9604 & -0.03153 & $4.86 \mathrm{E}-14$ & $1.4 \mathrm{E}-12$ & 1.89 \\
\hline 2 & 0.9668 & -0.02274 & 2.4 & $1.2510 \mathrm{ss}$ & 0 \\
\hline 3 & 0.9026 & -0.01048 & $1.15 \mathrm{E}-13$ & $4.33 \mathrm{E}-13$ & 4.5 \\
\hline 4 & 0.9702 & -0.0254 & $1.55 \mathrm{E}-15$ & $-9.4 \mathrm{E}-15$ & 1.95 \\
\hline 5 & 0.8436 & 0.087284 & 3.213 & 0.004826 & 0 \\
\hline 6 & 0.7858 & -0.00543 & $-1.1 \mathrm{E}-13$ & $-5.6 \mathrm{E}-13$ & 9.18 \\
\hline 7 & 0.9754 & 0.085714 & 0.8 & 0.583475 & 0 \\
\hline 8 & 0.9118 & -0.03631 & $4.09 \mathrm{E}-14$ & $9.21 \mathrm{E}-13$ & 1.545 \\
\hline 9 & 0.9546 & -0.08476 & 2.16 & 9.594193 & 1.545 \\
\hline 10 & 0.7598 & -0.10347 & $-1 \mathrm{E}-14$ & $-1.7 \mathrm{E}-13$ & 0 \\
\hline 11 & 0.7003 & -0.0065 & S.0SE-14 & $-1.2 \mathrm{E}-13$ & 2.424 \\
\hline 12 & 0.9176 & 0.08684 & 1.928 & 0.753387 & 0 \\
\hline 13 & 0.9731 & 0.085158 & $2.71 \mathrm{E}-13$ & 1.98E-13 & 2.292 \\
\hline 14 & 0.8760 & -0.07592 & 1.2 & -1.84677 & 0 \\
\hline 15 & 0.9055 & 0.085664 & $-7.3 \mathrm{E}-14$ & $-6.3 \mathrm{E}-14$ & 0 \\
\hline 16 & 0.7962 & -0.13836 & $-1.3 \mathrm{E}-13$ & $-1 \mathrm{E}-13$ & 1.146 \\
\hline 17 & 0.8338 & -0.03392 & $-3 \mathrm{E}-13$ & $-2.2 \mathrm{E}-13$ & 1.53 \\
\hline 18 & 0.9569 & -0.13756 & $-3.2 \mathrm{E}-14$ & $-2.4 \mathrm{E}-14$ & 0 \\
\hline 19 & 0.9506 & -0.03113 & 1.76 & 5.189297 & 1.89 \\
\hline 20 & 0.7517 & -0.07522 & $2.35 \mathrm{E}-13$ & $9.63 \mathrm{E}-14$ & 0 \\
\hline 21 & 0.7540 & 0.085614 & $-2.9 \mathrm{E}-13$ & $1.91 \mathrm{E}-13$ & 2.292 \\
\hline 22 & 0.9535 & -0.00585 & $-9.4 \mathrm{E}-14$ & $1.06 \mathrm{E}-12$ & 2.7 \\
\hline 23 & 0.7257 & -0.02394 & $-4.5 \mathrm{E}-13$ & $-4.6 \mathrm{E}-14$ & 0 \\
\hline 24 & 0.9691 & $-0.02655 \mid$ & $-4.6 \mathrm{E}-14$ & $-3.2 \mathrm{E}-13$ & 1.146 \\
\hline 25 & 0.8899 & -0.00946 & $-1.3 \mathrm{E}-13$ & $-6.3 \mathrm{E}-13$ & 3.6 \\
\hline 26 & 0.9436 & -0.02736 & 1.125 & 0.236856 & 0 \\
\hline 27 & 0.9621 & 0.083392 & $-2.2 \mathrm{E}-13$ & $-1.3 \mathrm{E}-13$ & 0 \\
\hline 28 & 0.8587 & -0.06639 & $9.88 \mathrm{E}-16$ & $2.81 \mathrm{E}-14$ & 0 \\
\hline 29 & 0.7720 & -0.10593 & $7.99 \mathrm{E}-15$ & $7.53 \mathrm{E}-14$ & 1.275 \\
\hline 30 & 0.9754 & -0.0242 & $-2.4 \mathrm{E}-14$ & $-1.7 \mathrm{E}-13$ & 1.95 \\
\hline 31 & 0.7431 & -0.02572 & $-1 \mathrm{E}-14$ & $-1.7 \mathrm{E}-13$ & 0.73725 \\
\hline 32 & 0.7991 & -0.02977 & $-2.7 \mathrm{E}-15$ & $-3.1 \mathrm{E}-14$ & 1.617 \\
\hline 33 & 0.9032 & -0.11249 & $7.24 \mathrm{E}-15$ & $-2.9 \mathrm{E}-14$ & 0 \\
\hline 34 & 0.8465 & -0.02361 & $7.82 \mathrm{E}-13$ & $5.08 \mathrm{E}-13$ & 1.2471 \\
\hline 35 & 0.9529 & -0.13943 & $-4.3 \mathrm{E}-14$ & $-3 \mathrm{E}-14$ & 0.615 \\
\hline 36 & 0.9801 & -0.02648 & 2.4 & 0.104634 & 0 \\
\hline 37 & 0.9529 & 0 & 46.0197 & 9.032308 & 0 \\
\hline 38 & 0.9853 & -0.14123 & $-1.9 \mathrm{E}-14$ & $2.61 \mathrm{E}-14$ & 0.573 \\
\hline 39 & 0.9639 & -0.03703 & $-5.1 \mathrm{E}-15$ & $-1.2 \mathrm{E}-14$ & 1.545 \\
\hline 40 & 0.9766 & -0.02195 & 2.4 & -0.33846 & 0 \\
\hline 41 & 0.9303 & -0.13818 & $4.2 \mathrm{E}-14$ & $1.86 \mathrm{E}-13$ & 1.548 \\
\hline 42 & 0.9673 & -0.04831 & $-6 \mathrm{E}-15$ & $1.44 \mathrm{E}-14$ & 1.8609 \\
\hline 43 & 0.9147 & -0.14204 & 1.104 & 1.672078 & 0 \\
\hline 44 & 0.9598 & -0.03259 & $1.42 \mathrm{E}-14$ & $8.36 \mathrm{E}-14$ & 0.91725 \\
\hline 45 & 0.8477 & -0.01242 & 4.56 & 0.542995 & 0.6225 \\
\hline 46 & 0.9587 & -0.01106 & $-6.5 \mathrm{E}-14$ & $3.14 \mathrm{E}-13$ & 6.29 \\
\hline 47 & 0.8205 & -0.53696 & $3.29 \mathrm{E}-13$ & $3.79 \mathrm{E}-14$ & 1.65 \\
\hline 48 & 0.9014 & -0.02617 & 4.416 & 0.667066 & 0.765 \\
\hline
\end{tabular}




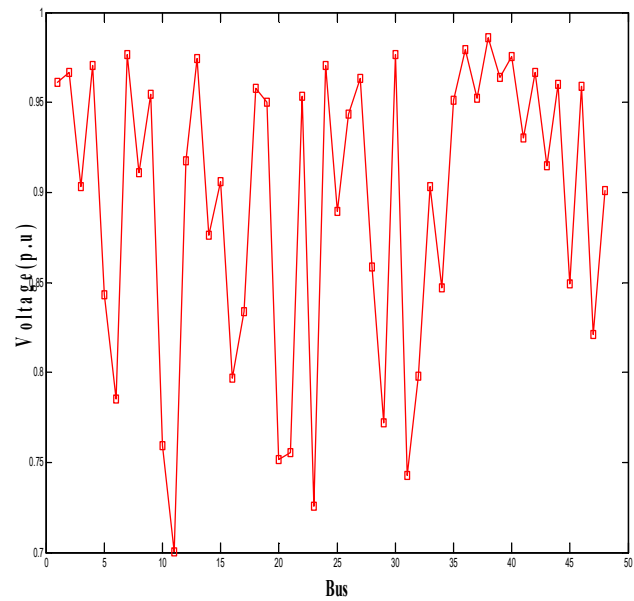

Figure. 4: Voltage Profile of the Base Case of Nigerian 330KV Power System

From the load flow result, it can be seen that 27 buses are below the 5\% voltage drop limit. This shows substantial weakness in the power system under investigation which might lead to instability.. However, this does not give much information regarding the distribution of instabilities in the system. Hence further simulations were carried out using the hybrid of Genetic and Arnoldi Eigenvalue analysis technique to find the eigenvalues, the damping ratios and the participation factors in the power system for proper placement of Power System Stabilizers Result of Pflw solution on outage of transmission line without stabilizer.

\subsection{Simulation and Analysis of Voltage Stability}

Simulations were carried out to determine the base voltage stability levels at the buses of the case study power system, and the ability of the system to operate stably and also to remain stable following the injection of simulated contingencies. The Eigenvalue analysis program was applied to the case study power system modeled in MATLAB simulink as shown in figure 2, The MATLAB m-file code of the eigenvalue program interfaces with the MATLAB/SIMULINK model of the case study power system via the MATLAB program Workspace.

The bus eigenvalues, bus participation factor, and bus damping ratios were computed for the case study power system base operational state (i.e. For the power system steady state - without contingency or disturbances) is listed in table 4.

Table 4: Load Flow Result for the Plot of the Profile of the Base Case Power System

\begin{tabular}{|c|c|c|c|c|}
\hline$\#$ & Bus\# & Eigen value $(\lambda)$ & Damping ratio(G) $1 \times 10^{-1}$ & Participation factor (\%) \\
\hline 1 & 8 & $-5.5957 \pm j 10.3330$ & 0.04762 & 0.0102 \\
\hline 2 & 9 & $2.325 \pm j 8.0321$ & 0.02781 & 2.0018 \\
\hline 3 & 10 & $-5.6837 \pm j 10.3601$ & 0.04810 & 0.2146 \\
\hline 4 & 11 & $-2.4892 \pm j 10.8650$ & 0.02233 & 10.1575 \\
\hline 5 & 12 & $-0.4087 \pm j 0.8293$ & 0.4421 & 0.0625 \\
\hline 6 & 13 & $-0.8922 \pm j 3.013$ & 0.2842 & 3.1174 \\
\hline 7 & 14 & $-5.3063 \pm j 10.3295$ & 0.4569 & 0.0625 \\
\hline 8 & 15 & $-5.1617 \pm j 11.2755$ & 0.4162 & 12.4678 \\
\hline 9 & 16 & $-0.4759 \pm j 0.5616$ & 0.6465 & 0.0933 \\
\hline 10 & 17 & $-04164 \pm j 0.6618$ & 0.5325 & 0.0536 \\
\hline 11 & 18 & $-2.0922 \pm j 7.914$ & 0.2562 & 2.0341 \\
\hline 12 & 19 & $-1.1731 \pm j 4.1051$ & 0.2751 & 4.3210 \\
\hline 13 & 20 & $-0.8042 \pm j 2.9632$ & 0.2623 & 0.7326 \\
\hline 14 & 21 & $-1.1843 \pm j 3.845$ & 0.2942 & 3.0072 \\
\hline 15 & 22 & $-1.1012 \pm j 3.1752$ & 0.3283 & 0.4136 \\
\hline 16 & 23 & $0.9499 \pm j 3.5917$ & 0.2552 & 2.0018 \\
\hline 17 & 24 & $-4.0428 \pm j 5.80451$ & 0.5716 & 1.4172 \\
\hline 18 & 25 & $-5.5160 \pm j 5.22030$ & 0.7108 & 8.3066 \\
\hline 19 & 26 & $-3.7688 \pm 0.0058$ & 0.5315 & 3.4172 \\
\hline 20 & 27 & 3.2505 t $\mathrm{j} 82795$ & 0.36543 & 0.9847 \\
\hline 21 & 28 & $-2.8394 \pm j 7.8648$ & 0.3396 & 2.6731 \\
\hline 22 & 29 & $-2.6431 \pm j 8.0318$ & 0.3126 & 0.9874 \\
\hline 23 & 30 & $-2.9202 \pm j 7.7275$ & 0.3536 & 0.0378 \\
\hline
\end{tabular}

The Eigenvalue $(\lambda)$ give information about the proximity of the system to instability. The participation factor measure the participation of a state variable in a certain mode of oscillation [12]. The bus participation factor 
shows the weak zones of the system (Montano et al, 2006). The branches and the generator participation factors shows transmission lines with the most reactive consumption and the generator that mainly supply reactive power back to the system[1]. The damping ratios $(\varsigma)$ is an indication of ability of the system to return to stable state in the event of disturbance.

\subsection{Contingencies without the Power System Stabilizers Installed/Outage of One Transmission Line}

A transmission line outage increases line impedance and weakens inter connection. Due to the increase in line reactance, extra reactive power is needed in other to maintain the voltage at the load buses. Here, the transmission outage simulation is performed by opening the line between bus 31 and bus 29 and reclosing it after five cycles. The circuit breaker in the SIMULINK library are configurable .The circuit breaker between bus31 and 29 was configured to open in 1 second and reclose after five cycle.

The Genetic Eigenvalue computation program was called during the simulation to compute the system eigenvalue, damping ratio and participation factor at the system buses. The power flow program was activated to carry out power flow solution of the current state of the power system. From result of the eigenvalue analysis almost all the real part of the complex eigenvalue listed in table 4 lie on the right half of the S-plain. That is the real parts of the complex eigenvalue are almost all positive. This is an indication that the system is unstable. The damping ratios of the eigenvalue are very small. The negative value of most of the damping ratios is a further indication of the instability of the system. Bus 11 shows the most negative (smallest) damping ratio (being the weakest bus even at steady state) the damping ratio of most of the buses in the power system during the disturbance are below the $5 \%$ minimum and the 0.2 damping threshold . The listing in table 5 confirms the information from the eigenvalue analysis.

The values in table 6 show that there is serious voltage degradation at the buses of the power system. The voltages in most of the buses are degraded. These result indicate that the exciters on the generators alone cannot stabilize the oscillation in the power system. The voltage magnitudes in table 6 do not give complete information of variation of voltage at the buses. The eigenvalues and the damping ratios indicates that the power system is unstable. This means that voltage at nodes of the power system are oscillating.

The trajectory of the voltage at the buses 11,15 and 23, as a result of the transmission line outage contingency, are shown on figures $5-7$ respectively.

Figures 8 -14, shows the load angle responses of generators 1, 3, 5, 7,9,11 and 13 respectively .Figures 15 17 shows the terminal voltage responses of generators 1,3 , and 5 respectively in that order to the transmission

Table 5: Eigenvalue and Damping Ratio of the case[9] Study Power System Buses during the Outage of the Transmission Line between Bus 31 and 29.

\begin{tabular}{|c|c|c|c|}
\hline S/No. & Bus No. & Eigen value $(\lambda)$ & Damping Ratio $(\varsigma)$ \\
\hline 1 & 1 & $0.1123 \pm \mathrm{j} 7.0876$ & 1.0675 \\
\hline 2 & 2 & $0.0448 \pm \mathrm{j} 4.0309$ & 0.0110 \\
\hline 3 & 3 & $0.5526 \pm \mathrm{j} 7.3025$ & 0.0135 \\
\hline 4 & 4 & $0.0547 \pm \mathrm{j} 3.2853$ & -0.0124 \\
\hline 5 & 5 & $0.0413 \pm \mathrm{j} 3.3227$ & 0.1035 \\
\hline 6 & 6 & $-0.5248 \pm \mathrm{j} 3.8483$ & -0.0057 \\
\hline 7 & 7 & $0.0014 \pm \mathrm{j} 2.5144$ & -0.0332 \\
\hline 8 & 8 & $0.1912 \pm \mathrm{j} 5.808$ & -0.0348 \\
\hline 9 & 9 & $0.1953 \pm \mathrm{j} 5.716$ & -0.022 \\
\hline 10 & 10 & $0.088 \pm \mathrm{j} 4.002$ & -0.4067 \\
\hline 11 & 11 & $0.4302 \pm \mathrm{j} 3.6798$ & -0.0013 \\
\hline 12 & 12 & $0.0281 \pm \mathrm{j} 2.0154$ & -0.0324 \\
\hline 13 & 13 & $-0.1212 \pm \mathrm{j} 3.7982$ & -0.0256 \\
\hline 14 & 14 & $0.0953 \pm \mathrm{j} 3.3835$ & -0.0225 \\
\hline 15 & 15 & $0.0883 \pm \mathrm{j} 4.0012$ & -0.005 \\
\hline 16 & 16 & $0.0335 \pm \mathrm{j} 6.852$ & -0.0017 \\
\hline 17 & 17 & $0.0658 \pm \mathrm{j} 3.7896$ & -0.3107 \\
\hline 18 & 18 & $0.2012 \pm \mathrm{j} 4.3186$ & -0.0108 \\
\hline 19 & 19 & $0.4029 \pm \mathrm{j} 3.1139$ & -0.2889 \\
\hline 20 & 20 & $0.0079 \pm \mathrm{j} 2.0146$ & -0.4011 \\
\hline 21 & 21 & $-0.1176 \pm \mathrm{j} 3.1134$ & -0.0003 \\
\hline 22 & 22 & $0.2021 \pm \mathrm{j} 2.0343$ & -0.2987 \\
\hline 23 & 23 & $0.3964 \pm \mathrm{j} 4.1342$ & -0.3421 \\
\hline 24 & 24 & $0.0788 \pm \mathrm{j} 3.4342$ & -0.0482 \\
\hline 25 & 25 & $0.1865 \pm \mathrm{j} 4.0072$ & \\
\hline
\end{tabular}




\begin{tabular}{|c|c|c|c|}
\hline S/No. & Bus No. & Eigen value $(\lambda)$ & Damping Ratio( $(s)$ \\
\hline 26 & 26 & $0.2108 \pm 3.3319$ & -0.0569 \\
\hline 27 & 27 & $0.0984 \pm \mathrm{j} 2.7934$ & -0.1867 \\
\hline 28 & 28 & $0.3012 \pm \mathrm{j} 4.4310$ & -0.3065 \\
\hline 29 & 29 & $0.0567 \pm \mathrm{j} 4.0173$ & -0.0768 \\
\hline 30 & 30 & $0.1684 \pm \mathrm{j} 3.1605$ & -0.1347 \\
\hline 31 & 31 & $0.2123 \pm \mathrm{j} 5.0876$ & 0.3675 \\
\hline 32 & 32 & $0.0478 \pm \mathrm{j} 3.0309$ & -0.2110 \\
\hline 33 & 33 & $0.5426 \pm \mathrm{j} 7.3025$ & 0.02137 \\
\hline 34 & 34 & $0.0647 \pm \mathrm{j} 3.2253$ & 0.0135 \\
\hline 35 & 35 & $0.0713 \pm \mathrm{j} 3.3427$ & -0.0424 \\
\hline 36 & 36 & $-0.7248 \pm \mathrm{j} 2.8783$ & 0.1135 \\
\hline 37 & 37 & $0.0014 \pm \mathrm{j} 2.5144$ & -0.0057 \\
\hline 38 & 38 & $0.1912 \pm \mathrm{j} 5.808$ & -0.0332 \\
\hline 39 & 39 & $-0.1953 \pm \mathrm{j} 5.716$ & -0.0348 \\
\hline 40 & 40 & $0.088 \pm \mathrm{j} 4.002$ & -0.022 \\
\hline 41 & 41 & $0.4302 \pm \mathrm{j} 3.6798$ & -0.3107 \\
\hline 42 & 42 & $0.0271 \pm \mathrm{j} 2.0154$ & -0.0313 \\
\hline 43 & 43 & $-0.1212 \pm \mathrm{j} 3.7982$ & -0.0324 \\
\hline 44 & 44 & $0.0753 \pm \mathrm{j} 3.3835$ & -0.0256 \\
\hline 45 & 45 & $0.0853 \pm \mathrm{j} 4.1012$ & -0.0227 \\
\hline 46 & 46 & $0.0335 \pm \mathrm{j} 6.852$ & -0.0015 \\
\hline 47 & 47 & $0.0658 \pm \mathrm{j} 3.7896$ & -0.0016 \\
\hline 48 & 48 & $0.3012 \pm \mathrm{j} 5.3186$ & -0.3089 \\
\hline & & & \\
\hline
\end{tabular}

Table 6: Result of Power Flow Solution of the Case Study Power System Buses During the Outage of Transmission Line between Bus 31 and 29

\begin{tabular}{|c|c|c|c|c|}
\hline Bus\# & Voltage magnitude (P.u) & Voltage angle ( rad ) & P(P.u) & Q(P.u) \\
\hline 1 & 0.7326 & -0.7817 & -0.5913 & -0.1086 \\
\hline 2 & 0.6979 & -0.5016 & -0.5344 & -0.1122 \\
\hline 3 & 0.9328 & -0.6943 & -0.7676 & -0.2697 \\
\hline 4 & 0.4513 & -0.7625 & -0.5347 & -0.0498 \\
\hline 5 & 1.1056 & -0.9227 & -0.4264 & -0.5617 \\
\hline 6 & 0.3696 & -0.3348 & -0.4128 & -0.9834 \\
\hline 7 & 0.4934 & -0.5812 & -0.4576 & -0.1307 \\
\hline 8 & 0.7579 & -0.3521 & -0.5504 & -0.1809 \\
\hline 9 & 1.2041 & -0.4817 & -0.5413 & -0.1086 \\
\hline 10 & 0.9873 & -0.4016 & -0.5644 & -0.1122 \\
\hline 11 & 0.3934 & -0.6243 & -0.7646 & -0.2607 \\
\hline 12 & 1.0034 & -0.4625 & -0.5347 & -0.0998 \\
\hline 13 & 0.4676 & -0.4227 & -0.4264 & -0.1017 \\
\hline 14 & 0.3696 & -0.3998 & -0.4128 & -0.1034 \\
\hline 15 & 0.4986 & -0.5012 & -0.4576 & -0.1507 \\
\hline 16 & 0.7579 & -0.4521 & -0.5504 & -0.1809 \\
\hline 17 & 0.6506 & -0.4332 & -0.4869 & -0.1264 \\
\hline 18 & 0.6347 & -0.3865 & -0.4337 & -0.1413 \\
\hline 19 & 0.9717 & -0.4386 & -0.5812 & -0.1118 \\
\hline 20 & 0.9681 & -0.3318 & -0.5795 & -0.0819 \\
\hline 21 & 0.8576 & -0.4626 & -0.4932 & -0.1338 \\
\hline 22 & 0.6792 & -0.3982 & -0.5216 & -0.2013 \\
\hline 23 & 0.4647 & -0.5984 & -0.6937 & -0.2446 \\
\hline 24 & 0.3120 & -0.3202 & -0.4827 & -0.1579 \\
\hline 25 & 0.4795 & -0.4529 & -0.4243 & -0.1834 \\
\hline 26 & 1.1052 & -0.4467 & -0.5006 & -0.1134 \\
\hline 27 & 0.5613 & -0.3846 & -0.5138 & -0.2007 \\
\hline 28 & 0.8819 & -0.4822 & -0.5623 & -0.1613 \\
\hline & & & & \\
\hline
\end{tabular}




\begin{tabular}{|c|c|c|c|c|}
\hline Bus\# & Voltage magnitude (P.u) & Voltage angle ( rad ) & P(P.u) & Q(P.u) \\
\hline 29 & 0.4982 & -0.4116 & -0.4985 & -0.1517 \\
\hline 30 & 0.6813 & -0.3976 & -0.5963 & -0.1549 \\
\hline 31 & 0.9326 & -0.7817 & -0.5913 & -0.1086 \\
\hline 32 & 1.0120 & -0.5016 & -0.5344 & -0.1122 \\
\hline 33 & 0.9328 & -0.6943 & -0.7676 & -0.2697 \\
\hline 34 & 1.0123 & -0.7625 & -0.5347 & -0.0498 \\
\hline 35 & 1.0234 & -0.9227 & -0.4264 & -0.5617 \\
\hline 36 & 0.7696 & -0.3348 & -0.4128 & -0.9834 \\
\hline 37 & 0.8934 & -0.5812 & -0.4576 & -0.1307 \\
\hline 38 & 1.0325 & -0.3521 & -0.5504 & -0.1809 \\
\hline 39 & 0.5326 & -0.4817 & -0.5413 & -0.1086 \\
\hline 40 & 0.9579 & -0.4016 & -0.5644 & -0.1122 \\
\hline 41 & 0.3248 & -0.6243 & -0.7646 & -0.2607 \\
\hline 42 & 1.0045 & -0.4625 & -0.5347 & -0.0998 \\
\hline 43 & 0.8676 & -0.4227 & -0.4264 & -0.1017 \\
\hline 44 & 0.4696 & -0.3998 & -0.4128 & -0.1034 \\
\hline 45 & 0.8934 & -0.5012 & -0.4576 & -0.1507 \\
\hline 46 & 1.2067 & -0.4521 & -0.5504 & -0.1809 \\
\hline 47 & 0.9506 & -0.4332 & -0.4869 & -0.1264 \\
\hline 48 & 1.0453 & -0.3865 & -0.4337 & -0.1413 \\
\hline
\end{tabular}

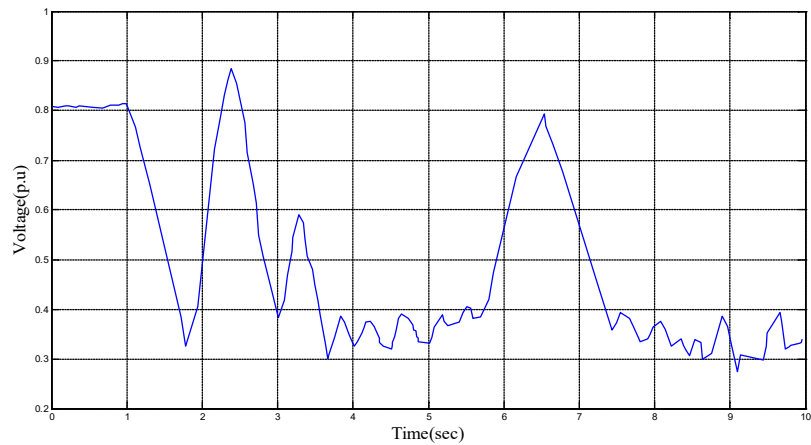

Figure5: Voltage Trajectory at Bus 11 during the Transmission Line Outage Contingency

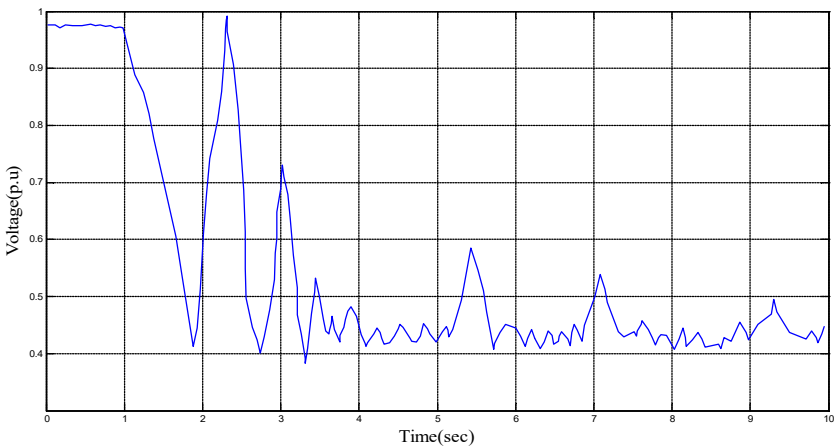

Figure 6: Voltage Trajectory at Bus 15 during the Transmission Line Outage Contingency 


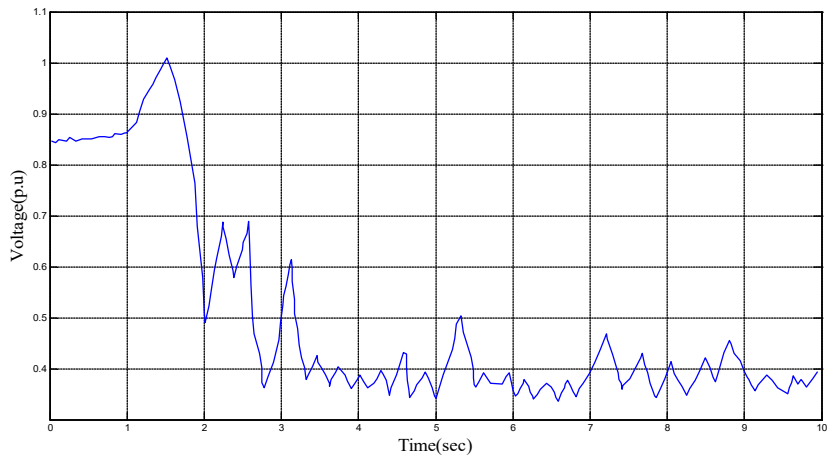

Figure 7: Voltage Trajectory at Bus 23 during the Transmission Line Outage Contingency

Figure 5 shows that at bus 11, in addition to voltage sag that began at time $1 \mathrm{sec}$, the voltage also oscillates as a result of the outage of the transmission line. It can be noticed in figure $5-7$ that before the outage the transmission line at $1 \mathrm{sec}$, the voltages are not experiencing noticeable instabilities (i.e the voltages are fairly stable around their various operating points). Before the outage, bus 11 voltage was at 0.813 p.uoperating point, while that of 15 , and 23 are around 0.987 p.u and 0.856 p.u respectively. However at the outage of transmission line at $1 \mathrm{sec}$, their voltage sagged and then oscillates.

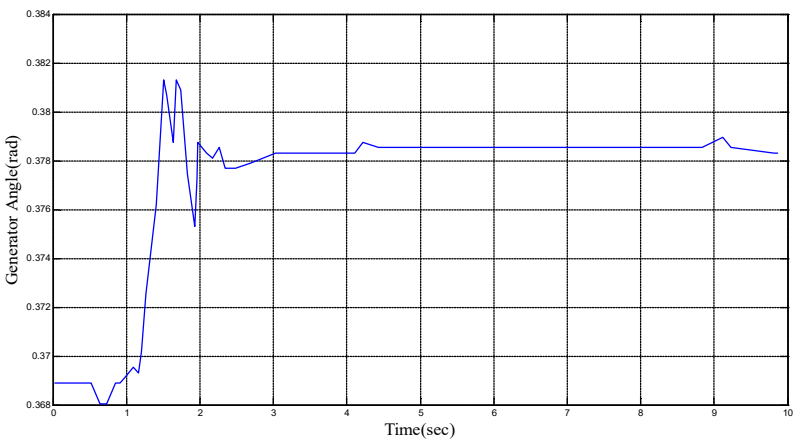

Figure 8: Generator 1 Angle Trajectory during Transmission Line Outage Contingency

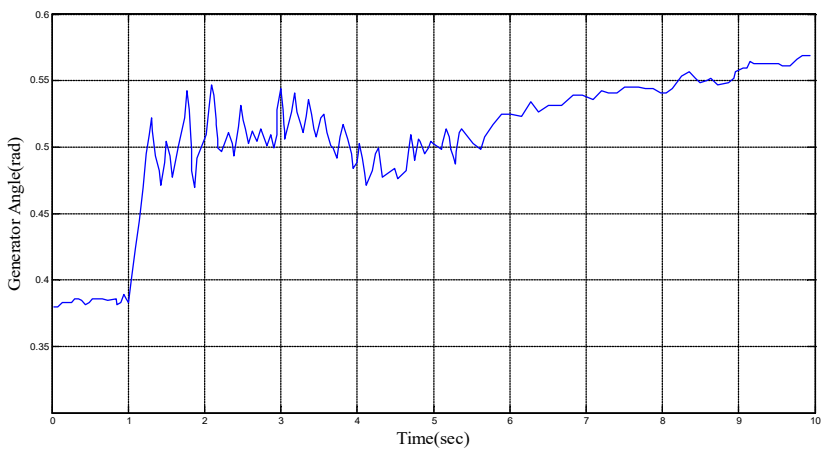

Figure 9: Generator 3 Angle Trajectory during Transmission Line Outage Contingency

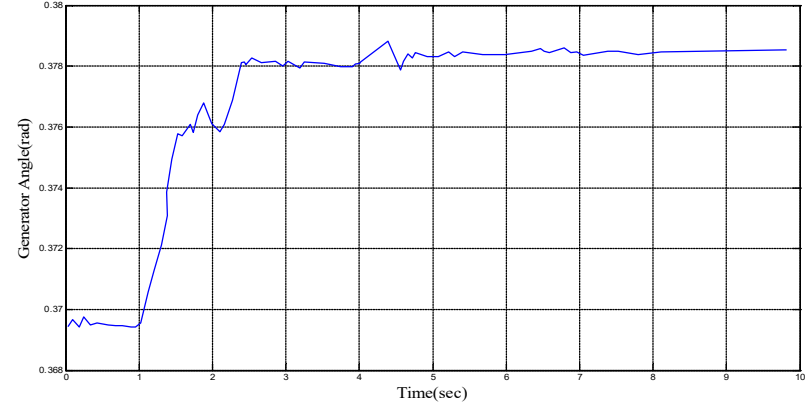

Figure10: Generator 5 Angle Trajectory during Transmission Line Outage Contingency 


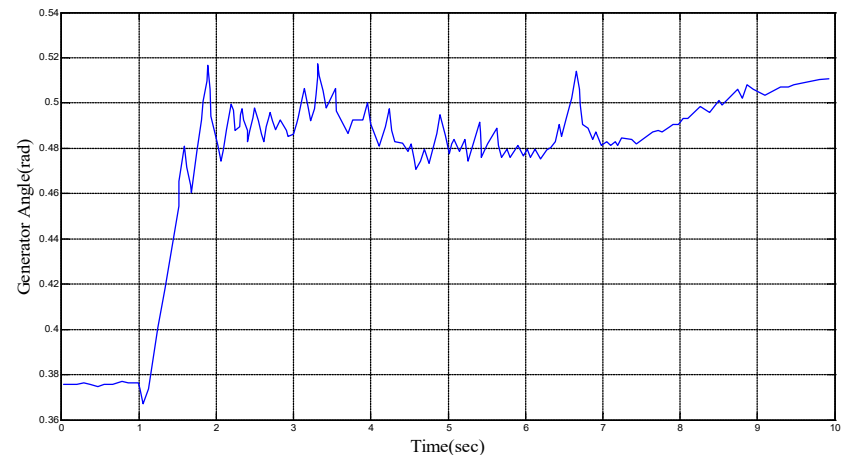

Figure11: Generator 7 Angle Trajectory during Transmission Line Outage Contingency

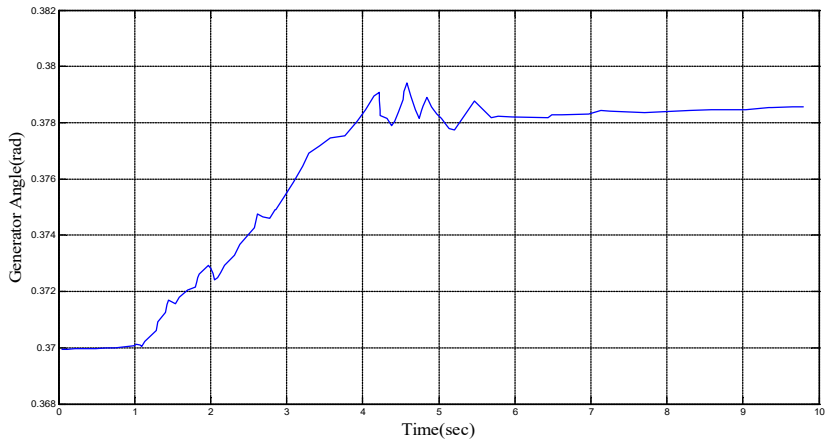

Figure 12: Generator 9 Angle Trajectory during Transmission Line Outage Contingency

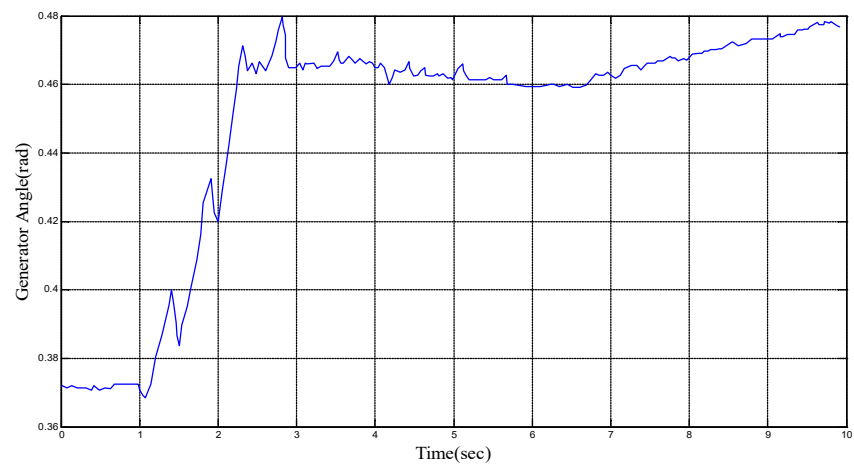

Figure 13: Generator 11 Angle Trajectory during Transmission Line Outage Contingency

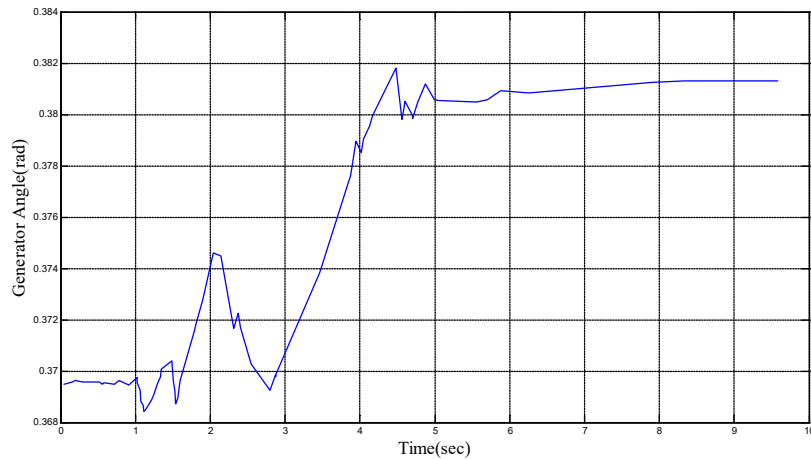

Figure 14: Generator 13 Angle Trajectory during Transmission Line Outage Contingency

From figure $8-14$, it can be seen that at $1 \mathrm{sec}$ into the simulation, from the time of transmission line outage, the angles of the generator rose then oscillates and tried to come to a new equilibrium. The larger the generator load angle, the closer it gets to the stability limit and the greater the danger of the generator falling out of 
synchronism with the rest of the power system. The rise and then oscillations of the generator angle as in figure 8 -14 indicates that the power system has become unstable.

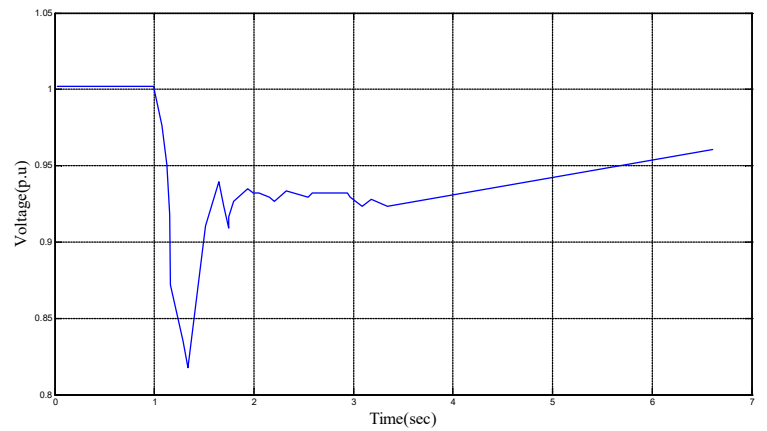

Figure 15: Generator 1 Terminal Voltage during Transmission Line Outage Contingency

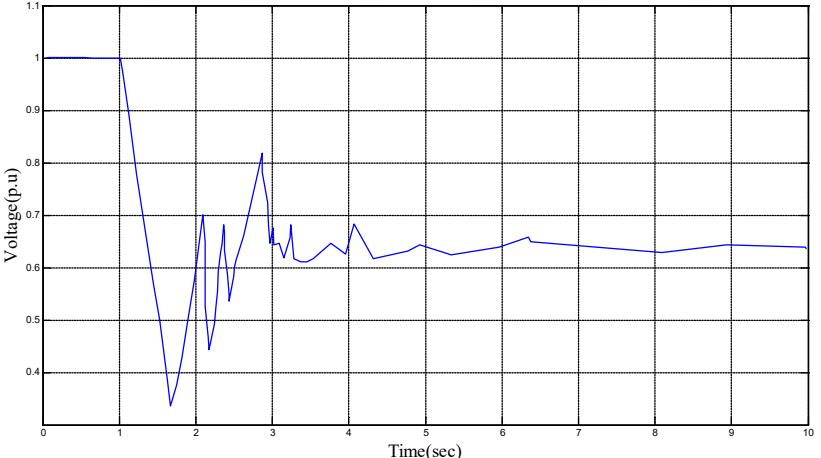

Figure 16: Generator 3 Terminal Voltage during Transmission Line Outage Contingency

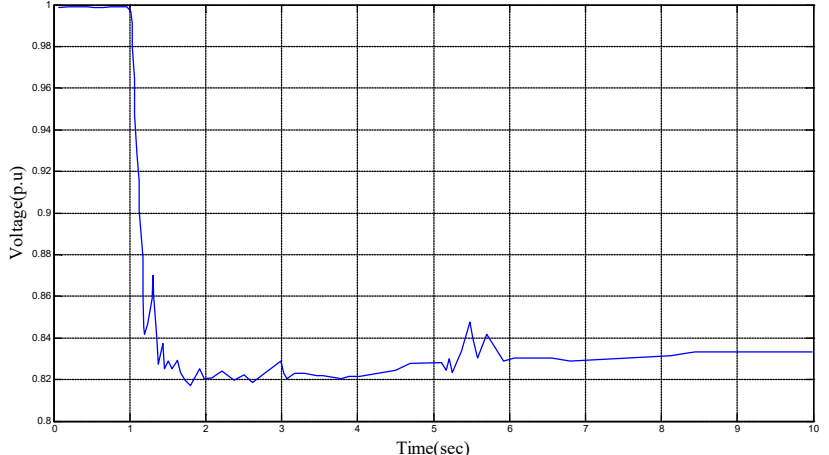

Figure 17: Generator 5 Terminal Voltage during Transmission Line Outage Contingency

The oscillation of the generator load angles is an indication of the generators' loss of synchronism with rest of the power system. The instabilities of the generators' terminal voltage as indicated in the oscillations of their terminal voltages (figure 15-17) indicates the failure of the generators excitation system and the generators AVRs to stabilize the generators output terminal voltages. These factors combine to cause the instabilities of the entire power grid as reflected in the eigenvalues and damping ratios of the buses in the power system.

The situation here requires the integration of the power system stabilizers to compliment the generator excitation system. The power system stabilizers will help to damp out the oscillations to the generator angle and the terminal voltages.

\section{Outage of a Power Plant}

The power system stability is now analyzed under generator outage condition. The MATLAB SIMULINK synchronous generator block was configured to trip the generator within a set time. The block is configured to trip generator 4 within $1.5 \mathrm{secs}$ of the simulation. The result of associated eigenvalue analysis is listed in table 8 
Table 7: Eigen values and damping ratios of the case study power system buses for the outage of generator 4.

\begin{tabular}{|c|c|c|c|}
\hline S/No. & Bus No. & $\operatorname{Eigen}$ value $(\lambda)$ & Damping Ratio(ৎ) \\
\hline 1 & 1 & $0.4806 \pm \mathrm{j} 8.1476$ & -0.7627 \\
\hline 2 & 2 & $0.46302 \pm \mathrm{j} 6.7734$ & -0.37414 \\
\hline 3 & 3 & $0.4564 \pm \mathrm{j} 5.3247$ & -0.3867 \\
\hline 4 & 4 & $0.3206 \pm \mathrm{j} 8.1476$ & -0.3627 \\
\hline 5 & 5 & $0.4465 \pm \mathrm{j} 4.8942$ & -0.4019 \\
\hline 6 & 6 & $0.4947 \pm \mathrm{j} 4.4366$ & -0.39434 \\
\hline 7 & 7 & $0.5367 \pm \mathrm{j} 4.3008$ & -0.3762 \\
\hline 8 & 8 & $0.4823 \pm \mathrm{j} 5.1163$ & -0.4918 \\
\hline 9 & 9 & $0.6975 \pm \mathrm{j} 63465$ & -0.5328 \\
\hline 10 & 10 & $0.6732 \pm \mathrm{j} 6.2248$ & -0.5562 \\
\hline 11 & 11 & $0.7806 \pm \mathrm{j} 8.1476$ & -0.7627 \\
\hline 12 & 12 & $0.7453 \pm \mathrm{j} 7.9969$ & -0.6834 \\
\hline 13 & 13 & $0.7113 \pm \mathrm{j} 6.9937$ & -0.7234 \\
\hline 14 & 14 & $0.7734 \pm \mathrm{j} 7.93644$ & -0.7274 \\
\hline 15 & 15 & $0.6973 \pm \mathrm{j} 6.9347$ & -0.6348 \\
\hline 16 & 16 & $0.7389 \pm \mathrm{j} 6.3021$ & -0.6849 \\
\hline 17 & 17 & $0.7546 \pm \mathrm{j} 7.3489$ & -0.6805 \\
\hline 18 & 18 & $0.6874 \pm \mathrm{j} 6.6534$ & -0.5964 \\
\hline 19 & 19 & $0.5686 \pm \mathrm{j} 7.7347$ & -0.5004 \\
\hline 20 & 20 & $0.6896 \pm \mathrm{j} 6.7347$ & -0.4908 \\
\hline 21 & 21 & $0.7834 \pm \mathrm{j} 8.2236$ & -0.6618 \\
\hline 22 & 22 & $0.7263 \pm \mathrm{j} 7.7993$ & -0.6536 \\
\hline 23 & 23 & $0.7658 \pm \mathrm{j} 8.8463$ & -0.6889 \\
\hline 24 & 24 & $0.6835 \pm \mathrm{j} 8.0013$ & -0.5876 \\
\hline 25 & 25 & $0.5342 \pm \mathrm{j} 6.1136$ & -0.4546 \\
\hline 26 & 26 & $0.6423 \pm \mathrm{j} 5.8376$ & -0.4987 \\
\hline 27 & 27 & $0.7102 \pm \mathrm{j} 6.3476$ & -0.6482 \\
\hline 28 & 28 & $0.6659 \pm \mathrm{j} 5.3426$ & -0.5586 \\
\hline 29 & 29 & $0.7508 \pm \mathrm{j} 6.3246$ & -0.6863 \\
\hline 30 & 30 & $0.7302 \pm \mathrm{j} 7.0034$ & -0.6537 \\
\hline 31 & 31 & $0.4706 \pm \mathrm{j} 8.1476$ & -0.5627 \\
\hline 32 & 32 & $0.36302 \pm \mathrm{j} 6.7734$ & -0.37414 \\
\hline 33 & 33 & $0.4564 \pm \mathrm{j} 5.3247$ & -0.3867 \\
\hline 34 & 34 & $0.3206 \pm \mathrm{j} 8.1476$ & -0.1627 \\
\hline 35 & 35 & $0.4465 \pm \mathrm{j} 4.8942$ & -0.4019 \\
\hline 36 & 36 & $0.6947 \pm \mathrm{j} 4.4366$ & -0.39434 \\
\hline 37 & 37 & $0.5367 \pm \mathrm{j} 4.3008$ & -0.3762 \\
\hline 38 & 38 & $0.4823 \pm \mathrm{j} 5.1163$ & -0.6918 \\
\hline 39 & 39 & $0.3975 \pm \mathrm{j} 63465$ & -0.5328 \\
\hline 40 & 40 & $0.6732 \pm \mathrm{j} 6.2248$ & -0.5562 \\
\hline 41 & 41 & $0.7806 \pm \mathrm{j} 8.1476$ & -0.7627 \\
\hline 42 & 42 & $0.6353 \pm \mathrm{j} 7.9969$ & -0.6834 \\
\hline 43 & 43 & $0.6813 \pm \mathrm{j} 6.9937$ & -0.7634 \\
\hline 44 & 44 & $0.2434 \pm \mathrm{j} 7.93644$ & -0.2274 \\
\hline 45 & 45 & $0.5973 \pm \mathrm{j} 6.9347$ & -0.6348 \\
\hline 46 & 46 & $0.8389 \pm \mathrm{j} 6.3021$ & -0.4849 \\
\hline 47 & 47 & $0.2946 \pm \mathrm{j} 7.3489$ & -0.9805 \\
\hline 48 & 48 & $0.5174 \pm \mathrm{j} 6.6534$ & -0.2964 \\
\hline
\end{tabular}

From table 7, it can be seen that real part of the complex eigenvalues lie on the right-half of the S-plane. This shows that the real part of the complex eigenvalue are all positive. The damping ratios are all negative. This information indicates that the power system is unstable. Furthermore the instability from the generator outage seem to be more severe than that resulting from the transmission line outage. This is due to the fact that the real parts of the eigenvalue in table 7 of power plant outage are more positive that those of table 5 of transmission line outage, in addition the damping ratios listed in table 7 are more negative (smaller) than those listed in table 5. 
Table 8 gave the output of the power flow solution carried out by $\boldsymbol{P}$-flow using the generator outage disturbance data.

Table 8: Result of Power Flow Solution of Case Study System for the Outage of Generator 4

\begin{tabular}{|c|c|c|c|c|}
\hline Bus\# & Voltage magnitude (P.u) & Voltage angle ( $\mathrm{rad})$ & P(P.u) & $\mathrm{Q}(\mathrm{P} . \mathrm{u})$ \\
\hline 1 & 0.5427 & -0.7423 & -0.8347 & -0.1579 \\
\hline 2 & 0.4012 & -0.5276 & -0.9809 & -0.1834 \\
\hline 3 & 0.5867 & -0.9043 & -0.7643 & -0.1134 \\
\hline 4 & 0.4216 & -0.5646 & -0.6217 & -0.2007 \\
\hline 5 & 1.002 & -0.5267 & -0.5784 & -0.1613 \\
\hline 6 & 0.7017 & -0.4896 & -0.5629 & -0.1517 \\
\hline 7 & 0.1987 & -0.6876 & -0.6243 & -0.1549 \\
\hline 8 & 0.1996 & -0.6248 & -0.6543 & -0.1086 \\
\hline 9 & 1.0231 & -0.6423 & -0.6347 & -0.1122 \\
\hline 10 & 1.0012 & -0.5836 & -0.9809 & -0.2697 \\
\hline 11 & 0.2342 & -0.8643 & -0.7643 & -0.0498 \\
\hline 12 & 0.9978 & -0.5646 & -0.6217 & -0.5617 \\
\hline 13 & 0.2213 & -0.5967 & -0.5784 & -0.9834 \\
\hline 14 & 0.3017 & -0.4896 & -0.5629 & -0.1307 \\
\hline 15 & 0.3987 & -0.6876 & -0.6243 & -0.1809 \\
\hline 16 & 0.7996 & -0.6248 & -0.6543 & -0.1086 \\
\hline 17 & 0.2003 & -0.6024 & -0.5567 & -0.1122 \\
\hline 18 & 0.6876 & -0.4567 & -0.5243 & -0.2607 \\
\hline 19 & 0.9226 & -0.6132 & -0.6617 & -0.0998 \\
\hline 20 & 0.3672 & -0.4342 & -0.6834 & -0.1017 \\
\hline 21 & 0.3214 & -0.6182 & -0.6324 & -0.1034 \\
\hline 22 & 0.7186 & -0.4644 & -0.6685 & -0.1507 \\
\hline 23 & 0.3987 & -0.8835 & -0.7408 & -0.1809 \\
\hline 24 & 0.4236 & -0.4263 & -0.6847 & -0.1264 \\
\hline 25 & 0.8106 & -0.6124 & -0.5246 & -0.1413 \\
\hline 26 & 0.3242 & -0.6245 & -0.6534 & -0.1086 \\
\hline 27 & 0.3743 & -0.4168 & -0.5965 & -0.1122 \\
\hline 28 & 0.5206 & -0.6428 & -0.6703 & -0.2697 \\
\hline 29 & 0.2459 & -0.5986 & -0.6136 & -0.0498 \\
\hline 30 & 0.3842 & -0.4857 & -0.6889 & -0.5617 \\
\hline 31 & 0.5427 & -0.7423 & -0.8347 & -0.9834 \\
\hline 32 & 0.2012 & -0.5276 & -0.9809 & -0.1307 \\
\hline 33 & 0.1867 & -0.9043 & -0.7643 & -0.1809 \\
\hline 34 & 1.0342 & -0.5246 & -0.6217 & -0.1086 \\
\hline 35 & 1.1056 & -0.5267 & -0.5784 & -0.1122 \\
\hline 36 & 0.7017 & -0.4896 & -0.5629 & -0.2607 \\
\hline 37 & 0.1987 & -0.6976 & -0.6243 & -0.0998 \\
\hline 38 & 1.1996 & -0.6248 & -0.6543 & -0.1017 \\
\hline 39 & 0.3427 & -0.6123 & -0.6347 & -0.1034 \\
\hline 40 & 0.2012 & -0.5436 & -0.9809 & -0.1507 \\
\hline 41 & 0.1867 & -0.8643 & -0.7643 & -0.1809 \\
\hline 42 & 1.0342 & -0.5646 & -0.6217 & -0.1264 \\
\hline 43 & 0.4213 & -0.5967 & -0.5784 & -0.1413 \\
\hline 44 & 0.3017 & -0.4896 & -0.5629 & -0.1118 \\
\hline 45 & 0.2987 & -0.6876 & -0.6243 & -0.0819 \\
\hline 46 & 1.1906 & -0.6248 & -0.6543 & -0.1338 \\
\hline 47 & 0.2003 & -0.6024 & -0.5567 & -0.2013 \\
\hline 48 & 0.2876 & -0.4567 & -0.5243 & -0.2446 \\
\hline
\end{tabular}

The voltage magnitude listed in table 8 is in line with the information from the eigenvalue and damping ratios in table 7. The voltage magnitude in table 8, indicates serious degradation in the bus voltage as a result of the power plant outage. A comparison of the levels of voltage degradation in tables 6 , and table 8 showed that the severity of the voltage degradation is more than that in table 6.The severity of the degradation is worse than that of the base power system. For instance referring to the voltage levels in the result of the power flow solution in 
tables 6 , it can be seen that for the transmission line outage contingency, the voltage of bus 11 stood at 0.3934 p.u , that of bus 15 stood at $0.4986 \mathrm{p}$.u and that of bus 23 stood at 0.4647 after the transmission line outage contingency. However for the power plant outage table 4.13, the voltage of bus 11 stood at 0.2342 p.u, that of bus 15 stood at 0.3987 p.u while that of bus 23 stood at 0.3987 p.u. The margin gives an indication of the level of severity of the instability resulting from the outage of the power plant. This fact is shown by the very high negative damping ratio resulting from all the real parts of the bus eigenvalues lying on the right-half of the S-plane. The real parts of the eigenvalue in table 5 are very much positive than the real parts of the eigenvalues in table 7.

Figures $5-7$ are the trajectories of the voltages at bus 11,15 and 23 respectively as the result of the outage of generator 4. The trajectories of the load angles of generator 2, 3, 5, 6, 7 and 8 as a result of the outage of generator 4 are shown by figures $21-23$.

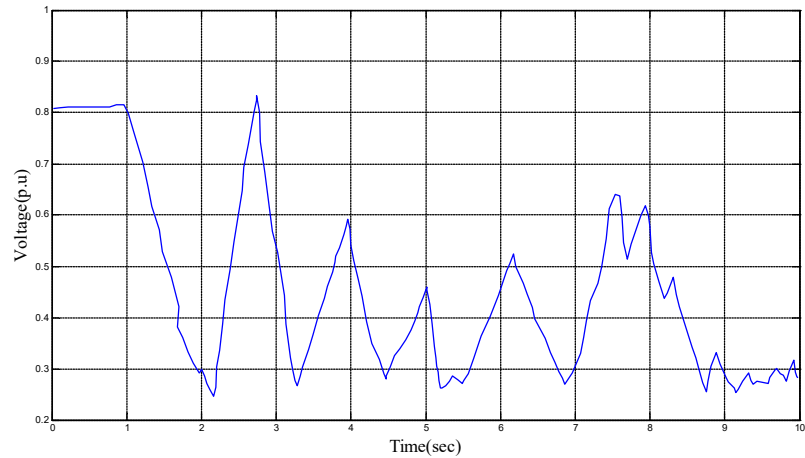

Figure 18: Voltage Trajectory at Bus 11 during the Power Plant Outage Contingency

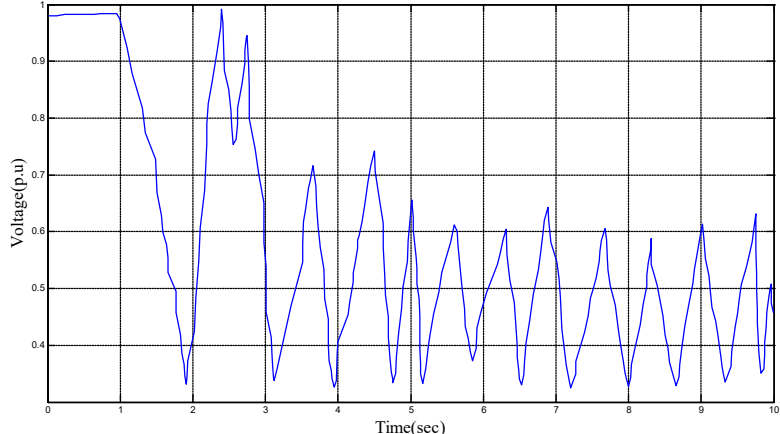

Figure 19: Voltage Trajectory at Bus 15 during the Power Plant Outage Contingency

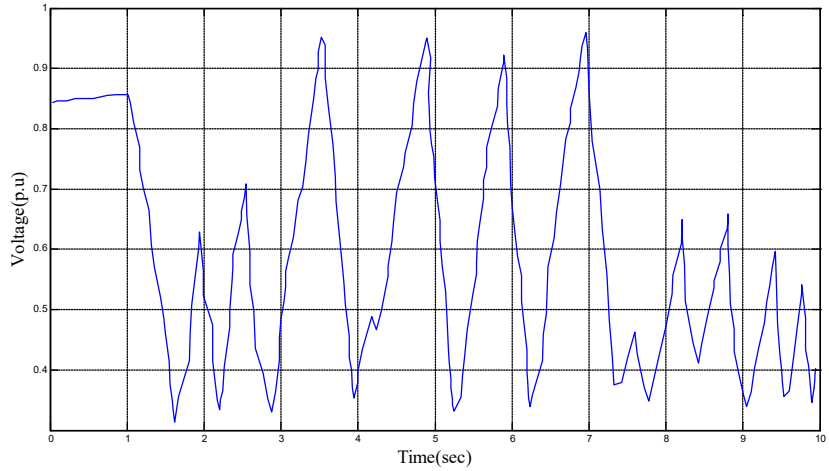

Figure 20: Voltage Trajectory at Bus 23 during the Power Plant Outage Contingency 


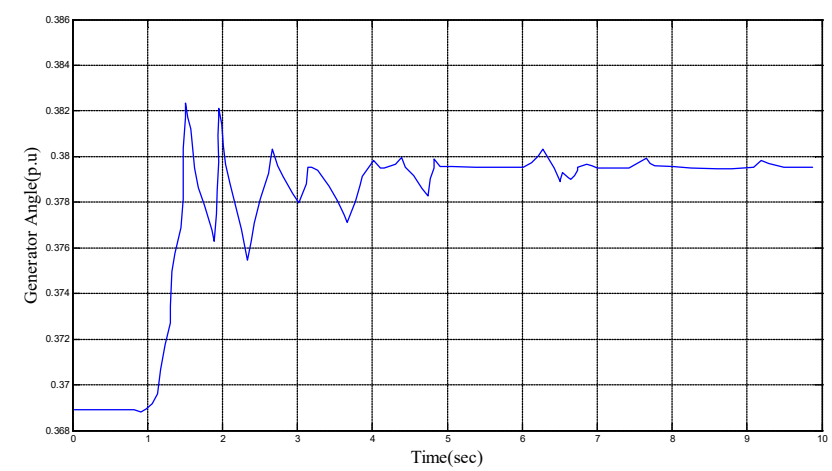

Figure 21: Generator 1 Angle Trajectory during Power Plant Outage Contingency

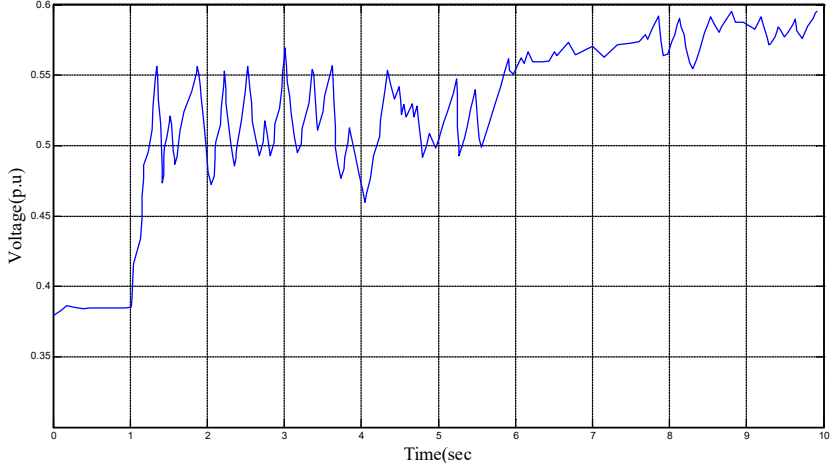

Figure 22: Generator 3 Angle Trajectory during Power Plant Outage Contingency

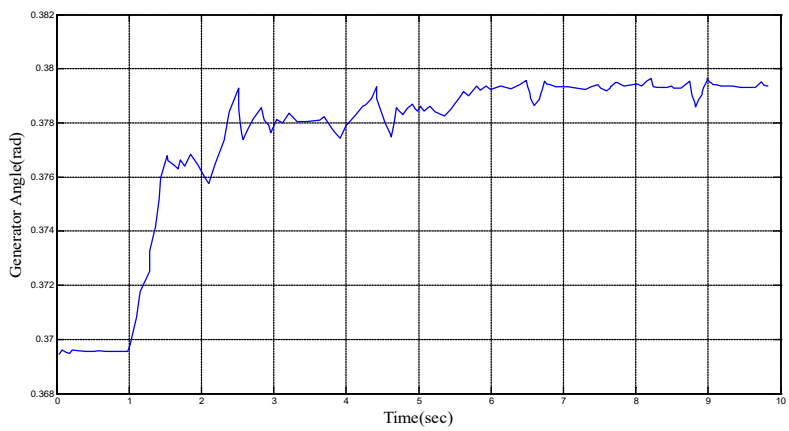

Figure 23 Generator 5 Angle Trajectory during Power Plant Outage Contingency

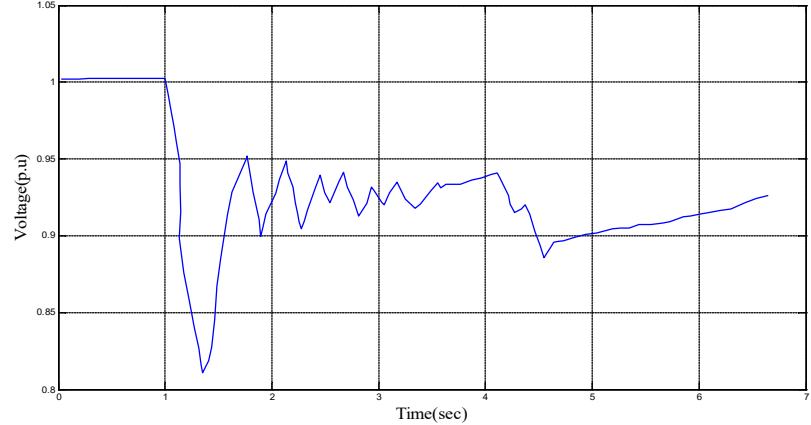

Figure 24: Generator 1 Terminal Voltage during Power Plant Outage Contingency 


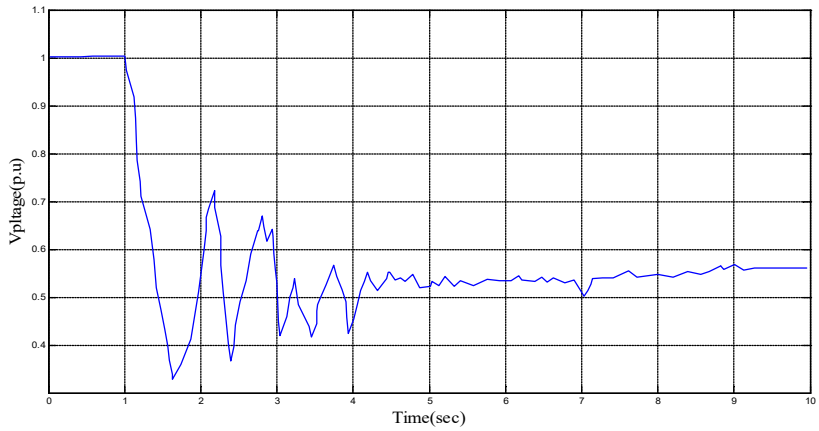

Figure 25: Generator 3 Terminal Voltage during Power Plant Outage Contingency

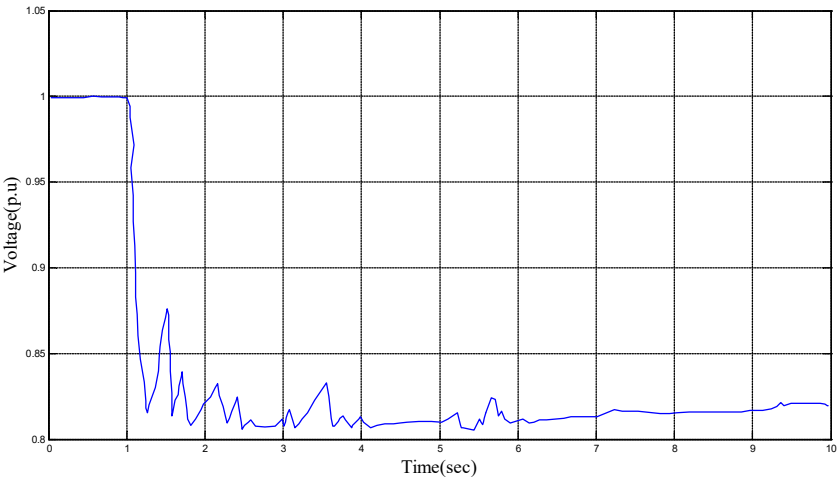

Figure 26: Generator 5 Terminal Voltage during Power Plant Outage Contingency

Figure 18 - 20 showed that the impact on the voltage levels and their stability is more severe than those of figure 5-7 in the case of the transmission line outage.

Figure $18-20$ indicate that the voltage instability of the power system is (as seen in the level of voltage oscillations) is higher than when the power system was impacted by the transmission line outage.

The same can be said of the severity of the instability of the load angle of the generator as shown in figure $21-23$ (for generators 1,3 , and 5), when compared to the instabilities in the case of the transmission line outage as shown in figure 8-10. As figures 24-26 indicate the terminal voltages of the generators were heavily impacted by the power plant outage contingency more than they were impacted by the transmission line outage contingency as shown in figure $15-17$. These results agree with the eigenvalue and damping ratio computed for the case of the transmission line outage event and the power plant outage event on the case study power plant

\section{1 conclusion}

It is very important to re-establish baseline values for key stability parameters for the Nigerian power system. This will enable the establishment of ground of service assessment index. From the Eigenvalue and power flow resultsof the transmission line voltage trajectories, generator terminal voltages and load angles, it is observed that the contingency impact on power plant is more severe than that of the transmission lines. This demands the need to use appropriate technique for a choice of selection of stability analysis for placement of PSS on generators with high participation factor to support the exciters of the generators. Genetic eigenvalue technique is recommended for its heuristic behavior in optimal location of eigenvalues.

\section{References}

1.Gao B., Morison G.K., \&Kundar P., "Voltage Stability Evaluation using Modal Analysis", IEEE Transaction on Power System Vol. 7, No 4,Nov.,1992.

2.Hoang P \& Tomsovic K, Design and analysis of an adaptive fuzzy power system stabilizer, IEEE Transactions on Energy Conversion, 11(2), pp. 97-103,1996.

3.Kundur P. Dandeno P. L, , Lee D. C, Bayne J. P, "Impact of turbine generator controls on unit performance under system disturbance conditions," IEEE Trans. Power Apparatus and Systems, vol. PAS-104, pp. 1262 1267, June, 2005.

4.Liu D., \&Cai Y., "Taguchi method for solving the economic dispatch problem with non-smooth cost functions", IEEE Trans. Power Syst., Vol. 20, No. 4, pp. 2006-2014, 2014

5.Lokman H. Hassan, M. Moghavvemi, Haider A.F. Almurib, K. M. Muttaqi, “A Coordinated Design of PSSs and 
UPFC-based Stabilizer Using Genetic Algorithm”, 10.1109/TIA .2305797, IEEE Transactions on Industry Applications, 2014.

6. Lu J, Chiang H.D, and Thorp J.S., Identification of optimum sites for power system stabilizer applications, IEEE Transactions on Power Systems, vol. 5, no. 4, pp. 1302- 1308, May, 2016.

7.Machowski J., Power System Dyromres Stability and Control, United Kingdom John Wiley and Sons, Ltd, 2008. 8.ManishaDubey. (2018), "Design of Genetic Algorithm Based Fuzzy Logic Power System Stabilizers in Multimachine Power System”, 978-1-4244-1762-9/08/\$25.00 C IEEE, June, 2018.10.

9.Martins N and Lima L. T. G, "Determination of suitable locations for power system stabilizers and static VAR compensators for damping electromechanical oscillations in large scale power systems," IEEE Transactions on Power Systems, vol. 5, no. 4, pp. 1455-1469. April, 2018.

10.Maslennikov V. A. and Ustinov S. M, "The optimization method for coordinated tuning of power system regulators," in Proc. 12th Power Syst. Comput. Conf. PSCC, 1996.

11.Zhou E Z., O. P. Malik, and Hope G.S., "Theory and method for selection of power system stabilizer location", IEEE Transactions on Energy Conversion, vol. 6, no. 1, pp. 170-176, 2017.

7. Mariano, S.J.P.S., Pombo, J.A.N., Calado M.R.A., Ferreira, L.A.F.M. (2010) , "Pole-shifting Procedure to specify the Weighting Matrices for an Optimal Voltage Regulator" International Review of Automatic Control (Theory and Applications), Vol. 2. n. 6, pp. 685-692. 